\title{
Alleviatory effects of Danshen, Salvianolic acid A and Salvianolic acid B on PC12 neuronal cells and Drosophila melanogaster model of Alzheimer's disease.
}

\section{Author names}

Florence Hui Ping TAN ${ }^{1,2}$ (ORCiD ID: 0000-0001-7273-1847), Andrew Chung Jie TING ${ }^{1}$ (ORCiD ID: 0000-0003-4202-6199), Nazalan NAJIMUDIN ${ }^{1,2}$, Nobumoto WATANABE ${ }^{2,3}$ (ORCiD ID: 00000002-2130-1334), Ghows AZZAM ${ }^{1,2 *}$ (ORCiD ID: 0000-0001-5352-8675)

\section{Affiliation}

${ }^{1}$ School of Biological Sciences, Universiti Sains Malaysia, 11800 Penang, Malaysia

${ }^{2}$ USM-RIKEN International Centre for Ageing Science (URICAS), Universiti Sains Malaysia, 11800

Penang, Malaysia

${ }^{3}$ Bioprobe Application Research Unit, RIKEN Centre for Sustainable Resource Science, RIKEN, Japan.

\section{Corresponding author}

Ghows AZZAM ${ }^{1,2 *}$

Email: ghows@usm.my; Tel: +604 6534005

\section{Keywords}

Danshen, Salvianolic acid A, Salvianolic acid B, Drosophila melanogaster, Alzheimer's disease 


\begin{abstract}
Alzheimer's disease (AD) is the most common form of neurodegenerative disorder worldwide. Its pathogenesis involves the hallmark aggregation of amyloid-beta $(A \beta)$. Of all the $A \beta$ oligomers formed in the brain, $A \beta 42$ has been found to be the most toxic and aggressive. Despite this, the mechanism behind this disease remains elusive. With the ability to utilize various genetic manipulations, Drosophila melanogaster is ideal in analysing not only cellular characteristics, but also physiological and behavioural traits of human neurodegenerative diseases. Danshen water extract (DWE), obtained from the root of Salvia miltiorrhiza Bunge, was found to have a vast array of beneficial properties. In this study, DWE, and its major components, Salvianolic acid A (SalA) and Salvianolic acid B (SalB) were tested for their abilities to ameliorate A $\beta 42$ 's effects. DWE, SalA and SalB were confirmed to be able to reduce fibrillation of $A \beta 42$. As $A \beta 42$ causes neurodegeneration on neurons, DWE, SalA and SalB were tested on A $\beta 42$-treated PC12 neuronal cells and were shown to increase cell viability. DWE and its components were then tested on the Drosophila melanogaster AD model and their rescue effects were further characterized. When human A $\beta 42$ was expressed, the Drosophila exhibited degenerated eye structures known as the rough eye phenotype (REP), reduced lifespan and deteriorated locomotor ability. Administration of DWE, SalA and SalB partially reverted the REP, increased the age of AD Drosophila and improved most of the mobility of AD Drosophila. In conclusion, DWE and its components may have therapeutic potential for AD patients and possibly other forms of brain diseases.
\end{abstract}

\title{
Introduction
}

The natural progression of aging has been a risk factor to age-related ailments such as dementia, with Alzheimer's disease (AD) being the most common form (Ferri et al., 2005; Hung et al., 2010). AD is a neurodegenerative disease clinically depicted as a gradual and progressive decline in cognitive function (Murphy \& LeVine, 2010). AD patients often encounter a range of symptoms such as behavioural changes to motor deterioration, and ultimately the inability to perform the simplest tasks. There are several hypotheses behind the occurrence of $\mathrm{AD}$, with the two most established hypotheses being amyloid aggregation and tauopathy (Ittner \& Götz, 2011; Tan \& Azzam, 2017). Currently there are a few United States Food and Drug Administration (FDA)-approved drugs, however, all of which could only temporarily lessen AD symptoms. The inadequate understanding on the exact cause of $\mathrm{AD}$ affects the advancement of effective drugs (Knopman, 2006). Hence, are we looking into compounds that can potentially treat $\mathrm{AD}$.

Here, we are using Drosophila melanogaster as the model organism to test the compounds of interest as it has been extensively utilized to study human disorders which includes neurodegenerative diseases such as AD (Moloney et al., 2010; Tan \& Azzam, 2017). A key feature of using D. melanogaster is its short lifespan, requiring about 10 days to reach adulthood from egg (Helfand \& Rogina, 2003; Sun et al., 2013; Tan \& Azzam, 2017). The simple anatomy as well as genetic characteristics of $D$. melanogaster further supports its role as an ideal model for diseases. While it has fewer genes compared to C. elegans, $D$. melanogaster has 196 out of 287 recognised human disease genes homologues (St Johnston, 2002; Tan \& Azzam, 2017). Furthermore, gene characterisation in D. melanogaster is simpler due to it having less genetic redundancy compared to vertebrate models. Despite having a much simpler structured brain, it possesses similar characteristics to the central nervous systems of mammals. D. melanogaster also exhibit age-dependant behaviours and many 
cellular processes which are involved in neurodegeneration. (McGurk et al., 2015; Tan \& Azzam, 2017).

The dried root of red sage (Salvia miltiorrhiza) or generally known as Danshen is a popular traditional Chinese medicine used in clinical applications for over 1, 000 years (Chen et al., 2014). Its popularity is credited to its usage in the treatment of many diverse diseases such as AD, Parkinson's disease, cerebrovascular disease as well as coronary heart disease (Zhou et al., 2005; Su et al., 2015). With over 100 isolated components (Pang et al., 2016), Danshen has a huge array of secondary metabolites with two dominant secondary metabolites classes; diterpenoids and phenolic acids (Su et al., 2015; Hügel \& Jackson, 2014; Mei et al., 2019). Phenolic acids which include Salvianolic Acid A (SalA) and Salvianolic Acid B (SalB) to name a few, possess wide biological activities such as anti-oxidative, anti-coagulation as well as anti-inflammatory (Mei et al., 2019; Jiang et al., 2005). In this study, we will look at the effect of Danshen water extract, and its components SalA and SalB, in elucidating their protective roles against A $\beta 42$-associated neurodegeneration using Drosophila AD model.

\section{Materials and Methods}

\section{Compounds}

Danshen water extract (DWE), Salvianolic acid A (SalA) (CAS no.: 96574-01-5) and Salvianolic acid B (SalB) (CAS no.: 115939-25-8) were obtained from LifeTech Solution Venture, Malaysia and were prepared in $0.5 \%$ dimethyl sulfoxide (DMSO) unless stated otherwise. Purities for SalA and SalB were over 98\%. HPLC-grade formic acid was obtained from Merck while HPLC-grade acetonitrile was bought from Fisher Chemical.

\section{Preparation of Aß42}

A $\beta 42$ was purchased from Anaspec (Cat no.: AS-20276) and $1 \mathrm{mg}$ of the peptide dissolved in $1 \mathrm{~mL}$ of $100 \%$ DMSO. The peptide was kept in aliquots of $50 \mu \mathrm{L}$ at $-80{ }^{\circ} \mathrm{C}$ until further use.

\section{Thioflavin T (THT) Aß42 Aggregation assay}

ThT assays were performed using the SensoLyte ${ }^{\circledR}$ Thioflavin $T \beta$-Amyloid $(1-42)$ Aggregation Kit (Anaspec, Cat no: AS-72214) with slight modifications to the manufacturer's protocol. In a black 96 well-plate, $\mathrm{A} \beta 42$ (Volume: $42.5 \mu 1$, final concentration $=42.5 \mu \mathrm{M}$ ) was added to the compounds (Volume: $2.5 \mathrm{ul}$, final concentration $=$ $1 \mathrm{mg} / \mathrm{ml}$ ). Thioflavin $\mathrm{T}$ (Volume: $5 \mu \mathrm{l}$, final concentration $=20 \mu \mathrm{M}$ ) was the added in a dark room. The fluorescence reading was read using the Biotek Synergy 2 SLFP Multimode Microplate Reader every 300 seconds for a total of 3600 seconds at an excitation/emission of $440 \mathrm{~nm} / 484 \mathrm{~nm}$ with pulsed shaking in between at $37{ }^{\circ} \mathrm{C}$. The commercially available compound Morin (Volume: $2.5 \mu \mathrm{l}$, final concentration $=50 \mu \mathrm{g} / \mathrm{ml}$ ) was used as the positive control. 


\section{PC12 cell culture husbandry}

Rat pheochromocytoma PC12 cells were obtained from the RIKEN Cell Bank (Tsukuba, Ibaraki, Japan). The cells were cultured routinely in Dulbecco`s Modified Eagle Media (DMEM) (Gibco, Cat no.: C11995500BT) supplemented with 10\% Fetal bovine serum (Sigma Chemical Co. St Louis, MO, USA, Cat no.: 172012) and 10\% Horse serum (Gibco, Cat no.: 26050-070) in a humidified atmosphere of 5\% CO2 at $37{ }^{\circ} \mathrm{C}$. To differentiate $\mathrm{PC} 12$ neuronal cells, cultures were provided with DMEM containing 10\% Horse serum and 100 ng/mL Nerve Growth Factor (Sigma Chemical Co. St Louis, MO, USA, Cat no.: H966610UG).

\section{Cell viability determination by ATP assay}

$\mathrm{A} \beta$ was added with respective compounds and aged for 72 hours at $37^{\circ} \mathrm{C}$ (Moreira et al., 2007). Cells were seeded in white 96 clear bottom well plates at $5 \times 10^{3}$ densities per $100 \mu 1$ with complete media. After 24 hours, the media was replaced with differentiation media and cells were incubated for 72 hours. $\mathrm{A} \beta$ (Final concentration $=10 \mu \mathrm{M}$ ) with respective compounds (Final concentration $=50 \mu \mathrm{M}$ ) were added to the wells and incubated for 24 hours. Equal amounts of CellTiter-Glo (Promega, Cat no: G7570) were added to the wells. The plate was shaken for 2 minutes and was left to stand in room temperature for 10 minutes. Luminescence reading was taken using Varioskan ${ }^{\mathrm{TM}}$ LUX multimode microplate reader. The experiment was done in triplicates.

\section{Drosophila Stocks and Husbandry}

All Drosophila stocks used in this study are listed in Flybase (http://fybase.bio.indiana.edu). The following stocks were obtained from Bloomington Drosophila Stock Center (Bloomington, U.S.A.): Oregon-R wild type (\#5), Glass Multiple Reporter-GAL4 (\#1104) and UAS-Aß42 (\#33769) while Actin5C-GAL4 (\#107727) was obtained from Kyoto Drosophila Genome and Genetic Resources (KGGR). All stocks were raised at $25{ }^{\circ} \mathrm{C}$ while crosses were kept at $29^{\circ} \mathrm{C}$. To prepare for crosses, 5-10 virgin Drosophila (Gal4 or UAS line) and 3-5 male Drosophila of the corresponding parent line were placed into plastic vials containing solid food. In general, Oregon-R was crossed with the specific GAL4 line of the particular analysis to produce GAL4-OreR whereas UAS-A $\beta 42$ was crossed with the specific GAL4 line to produce the transgenic Drosophila line GAL4-A $\beta 42$ that expressed A $\beta 42$. Table 1 depicts the progeny lines used in different analyses.

Solid cornmeal feed was prepared by boiling 4\% (w/v) corn starch, 5\% (w/v) polenta, 10\% $(\mathrm{w} / \mathrm{v})$ brown sugar, $0.7 \%(\mathrm{w} / \mathrm{v})$ agar, $5 \%(\mathrm{w} / \mathrm{v})$ inactivated yeast, $3 \%(\mathrm{w} / \mathrm{v})$ nipagin, $0.7 \%(\mathrm{v} / \mathrm{v})$ propionic acid and $0.5 \%$ (v/v) DMSO either alone (vehicle control) or containing the concentration of compound indicated in the text with constant mixing, before being aseptically transferred into plastic vials to be cooled and solidified. Liquid feed for the CApillary FEeder (CAFE) assay did not include cornmeal or agar: $5 \%(\mathrm{w} / \mathrm{v})$ yeast extract, $5 \%$ $(\mathrm{w} / \mathrm{v})$ glucose, $1.7 \%(\mathrm{w} / \mathrm{v})$ tryptone, $3 \%(\mathrm{w} / \mathrm{v})$ nipagin, $0.7 \%(\mathrm{v} / \mathrm{v})$ propionic acid and $0.5 \%$ $(\mathrm{v} / \mathrm{v})$ DMSO either alone (vehicle control) or containing the concentration of compound indicated in the text.

Conversely, an altered version of liquid feed with the addition of tryptone (Ja et al., 2007) for the CApillary FEeder (CAFE) assay was prepared without cornmeal and agar: $5 \%(\mathrm{w} / \mathrm{v})$ yeast extract, $5 \%(\mathrm{w} / \mathrm{v})$ glucose, $1.7 \%(\mathrm{w} / \mathrm{v})$ tryptone, $3 \%(\mathrm{w} / \mathrm{v})$ nipagin, $0.7 \%(\mathrm{v} / \mathrm{v})$ propionic acid 
and $0.5 \%$ (v/v) DMSO either alone (vehicle control) unless mentioned otherwise. Each capillary tube was filled with $10 \mu \mathrm{L}$ of liquid feed.

\section{External eye surface digital imaging and phenotypic analysis}

Light microscopy images were viewed using the stereo-motorized light microscope model Olympus SZX16 (Olympus Optical) attached with an Olympus DP72 camera (Olympus Optical). Images were taken with CellSens Dimesion version 1.5 (Olympus Optical). All light microscopy images have maximum magnifications of $11 x$.

For scanning electron microscopy (SEM), ten progenies from each group were fixed overnight at $4{ }^{\circ} \mathrm{C}$ in McDowell-Trump fixative (Sigma-Aldrich), containing $4 \%$ formaldehyde and $1 \%$ glutaraldehyde in $0.1 \mathrm{M}$ phosphate buffer (Sigma) $(\mathrm{pH} 7.2)$. The specimens were washed in phosphate buffer three times before being post-fixed in $1 \%(\mathrm{w} / \mathrm{v})$ osmium tetroxide (Sigma-Aldrich) at $25^{\circ} \mathrm{C}$ for an hour. The specimens were then washed with distilled water and dehydrated in a series of ethanol; 50\%, 75\%, 95\% and 100\% ethanol for 15 minutes each. The dehydrated specimens were immersed in hexamethyldisilazane (HMDS) (Sigma) for 10 minutes. The specimens were air-dried in a desiccator overnight. Dried specimens were then mounted, and gold coated to be viewed with SEM (SU8010; Hitachi Ltd., Tokyo, Japan).

Degree of ommatidia distortion was obtained from each image using a computational method called Flynotyper (https://flynotyper.sourceforge.net) through Image J that calculates a phenotypic score (P-value) (Iyer et al., 2018, 2016).

\section{CAFE Assay}

The CApillary FEeder (CAFE) assay (Ja et al., 2007) was modified and used throughout both the lifespan analysis and locomotive analysis. Using $15 \mathrm{~mL}$ falcon tubes, the bodies of the tubes were drilled with $1 \mathrm{~mm}$ diameter holes while four $2 \mathrm{~mm}$ diameter holes were drilled on the base of the caps to allow insertion of truncated $10 \mathrm{uL}$ pipette tips. Glass capillary tubes (Vitrex, Germany, Cat no.: 161313) filled with liquid feed by capillary action was inserted through the cap via the pipette tips. Capillaries were replaced every day. To facilitate egg laying, $1 \mathrm{~mL}$ of agar was added to all tubes.

\section{Lifespan Analysis}

For survival analysis, Actin5C-A $\beta 42$ Drosophila were collected within 24 hours from eclosion and transferred to the CAFE assay at standard density (less than 20 per vial) at $29^{\circ} \mathrm{C}$ and 60\% humidity. Dead Drosophila were counted daily. Surviving Drosophila were flipped to new vials and liquid feed with respective compounds was changed every day. The median lifespan corresponds to the day at which $50 \%$ of the Drosophila in a cohort is alive. The maximum lifespan is the day at which the last Drosophila in a cohort dies. To eliminate any variation caused by cytoplasmic background effects, all crosses were set up with female virgins from Actin5C-Gal4. Each line was done in triplicates $(\mathrm{n} \simeq 50$ in each replicate). Lifespans of each line were compared to Vehicle control (Actin5C-A $342 . D M S O$ ) line and tested for significance with log-rank test. 


\section{Measurement of Active compounds}

Ultra-Performance Liquid Chromatography (UPLC) analysis was executed using an Acquity Ultra Performance LC series (Waters) with an autosampler and an Acquity UPLC PDA UV detector (Waters) with an Acquity UPLC Column (Waters) $(50 \times 2.1 \mathrm{~mm})$. Analytical conditions consist of mobile phase A of $0.5 \%$ formic acid dissolved in water while mobile phase $B$ had an acetonitrile: water ratio of $95: 5$, at flow rate of $0.5 \mathrm{~mL} / \mathrm{min}$ and signals were detected at $288 \mathrm{~nm}$. The injection volume for all experiments was $2 \mu \mathrm{L}$. The gradient mode was implemented as follows: $5-20 \%$ of mobile phase B from 0 to $10 \mathrm{~min}, 20$ $25 \%$ of mobile phase B from 10 to $17 \mathrm{~min}$ and $25-55 \%$ of mobile phase B from 17 to $30 \mathrm{~min}$.

SalA and SalB concentrations were measured by UPLC. Briefly, a hundred adult Drosophila were decapitated and immersed in Ultra Pure H2O (Mayhems Solution Ltd). For food analysis, $2 \mathrm{~mL}$ of food was dissolved in Ultra Pure H2O (Mayhems Solution Ltd). For faecal analysis, a Q-tip was used to pick up faeces around the tube wall. The Q-tip was then immersed in Ultra Pure H2O (Mayhems Solution Ltd) for sample collection. All samples were homogenized for 5 minutes before freezing in $-80{ }^{\circ} \mathrm{C}$ for 2 hours. Frozen samples were freeze dried for 2 to 3 days until all traces of $\mathrm{H} 2 \mathrm{O}$ was gone. Samples were resuspended with suitable solvent and centrifuged to remove pellet. The supernatant was used for UPLC analysis. All standards were solubilized in Ultra Pure H2O (Mayhems Solution Ltd) at 1 $\mathrm{mg} / \mathrm{mL}$.

\section{Negative Geotaxis Assay}

Mobility of experimental Drosophila was measured in average climbing speed. The Drosophila were then tapped down on to the bottom of the vial at least 3 times before being allowed to scale the vial walls for 10 seconds. The videos of the Drosophila climbing up the vials were recorded and were analysed using the software ToxTrac (https://sourceforge.net/projects/toxtrac/ ) (Rodriguez et al., 2017, 2018). Examples of the videos can be found in the supplementary data.

\section{Results}

\section{DWE, SalA and SalB reduced aggregation of Aß42 in vitro}

To verify whether DWE and its components SalA and SalB influence the aggregation of $\mathrm{A} \beta 42$, they were first subjected to a primary screening via Thioflavin $\mathrm{T}$ (ThT). ThT binds to fibrillated aggregates whereby the dye experiences a characteristic red shift of its emission spectrum (Groenning, 2010). At specific time points, the fluorescence generated by ThT binding to amyloid fibrils were then measured and quantified. Decreasing fluorescence of ThT signified the test compound's ability to inhibit A $\beta 42$ aggregation. Morin was added as a positive control in the assay (Kapoor \& Kakkar, 2012).

At the time point of 3600 seconds, Morin reduced the RFU readings by $71.2 \%$ compared to DMSO. At the same time point, addition of DWE to A $\beta 42$ peptides decreased RFU readings by $36.9 \%$ while A $\beta 42$ peptides incubated with SalA and SalB experienced $65.9 \%$ and $50.8 \%$ decrement respectively in RFU readings when compared to the DMSO (Figure 1). This showed that DWE, SalA and SalB affected the aggregation of A $\beta 42$ by reducing the fibrillation. 


\section{DWE, SalA and SalB protected PC12 cells from Aß42-induced cell death}

To test the efficacy of DWE, SalA and SalB in cells, we tested the compounds using PC12 rat pheochromocytoma cells. The presence of A $\beta 42$ peptides decreased PC12 cell viability to $40 \%$ compared to the unexposed control $(\mathrm{p}=0.0022)$. However, this toxic effect was rescued with the supplementation of DWE and its components, SalA and SalB (Figure 2). The best rescue effect was exhibited by incubation with SalB in which cell viability was increased to $95.4 \%$ cell viability based on the control when compared to the A $\beta 42$-incubated PC12 cells supplemented with vehicle control $(\mathrm{p}=0.004)$. This was followed by SalB with a cell viability of $84 \%(p=0.0093)$ and DWE with cell viability of $73.5 \%(p=0.011)$. This demonstrated the ability of DWE, SalA and SalB to protect neuronal cells from the neurotoxicity effect of $\mathrm{A} \beta 42$.

\section{SalA and SalB were detected in the brains and bodies of Drosophila after DWE feeding}

In order to test the effect of these compounds on a whole organism, we chose Drosophila melanogaster as our model organism. As SalA and SalB are the two most abundant components in DWE (Ai \& Li, 1988; Lian-niang et al., 1984), their presence in various parts of DWE-fed Drosophila were analysed using UPLC. The retention time of SalA and SalB were 21.9 minutes (Figure 3Ai) and 20.7 minutes (Figure 3Aii) respectively. By comparing the retention time of both reference standards, DWE with a concentration of $10 \mathrm{mg} / \mathrm{ml}$ were found to have $43.0 \mu \mathrm{g} / \mathrm{ml}$ of SalA and $571 \mu \mathrm{g} / \mathrm{ml}$ of SalB.

Subsequently, one hundred Drosophila were fed with DWE and the heads, bodies and faeces were harvested and analysed through UPLC. For SalA, $0.85 \mu \mathrm{g} / \mathrm{ml}$ was detected in the heads, $4.3 \mu \mathrm{g} / \mathrm{ml}$ in the bodies and $37.3 \mu \mathrm{g} / \mathrm{ml}$ in the faeces. Likewise, the concentration of SalB in DWE-fed Drosophila heads, bodies and faeces were determined to be $2.6 \mu \mathrm{g} / \mathrm{ml}, 12.9$ $\mu \mathrm{g} / \mathrm{ml}$ and $407.1 \mu \mathrm{g} / \mathrm{ml}$, respectively. The data confirmed the presence of SalA and SalB in the heads and bodies of Drosophila after feeding of DWE.

\section{Effect of DWE, SalA and SalB on Drosophila melanogaster AD model}

The rough eye phenotype (REP) screening system was used to observe the effects of DWE, SalA and SalB on Drosophila, the rough eye phenotype (REP) (Kumar, 2012). The Drosophila eye is a model system to understand developmental neurobiology due to its simple neuroectoderm structure consisting of photoreceptors and accessory cells. Each eye comprised 800 hexagonal-shaped components known as ommatidium, organized in a crystalline array akin to the honeycomb cells of a beehive. These ommatidia are positioned in columns across the eye resulting in a concave "egg-like" formation (Figures 5A and 5A'). The mechano-sensory bristles extending at alternating vertices of each ommatidium that are directed at precise angles give an additional sensory field (Cagan, 2009; Cagan \& Ready, 1989; Kumar, 2012). As each ommatidium contains seven photoreceptor nerve cells, any distortion in the eye morphology could be attributed to abnormalities in the neurons (Basler et al., 1991; Tomlinson et al., 1987).

By using light micrographs, a strongly observable REP was seen when human A $\beta 42$ was ectopically expressed in the Drosophila eyes via the pan-retinal GMR-GAL4 driver (Figures 3B and 3B') (Finelli et al., 2004). When compared to the control GMR-OreR.DMSO (Figures $4 \mathrm{~A}$ and $4 \mathrm{~A}^{\prime}$ ), the GMR-A $\beta 42 . \mathrm{DMSO}$ adult eyes were severely malformed with merged ommatidia (Figures $4 \mathrm{~B}$ and $4 \mathrm{~B}^{\prime}$ ) 
The supplementation of transgenic Drosophila with different concentrations of DWE resulted in the partial rescue of eye deformation compared to that of GMR-A 342 .DMSO albeit at varying degrees (Figures 4C-E). As the dosage of DWE increased, the rescue effect on the eyes of the A 342 -expressing Drosophila fed with $10 \mathrm{mg} / \mathrm{mL}$ (Figure 4D) was more apparent showing similarity to those of the control GMR-OreR.DMSO (Figure 4A). However, the dosage of $20 \mathrm{mg} / \mathrm{mL}$ did not give an observable improvement on the eye (Figures $4 \mathrm{E}$ ). Similarly for both SalA (Figure 4F-3H) and SalB (Figure 4I-3K) treatments, there was a recovery in eye morphology when transgenic Drosophila were cultured in $100 \mu \mathrm{M}$ of compounds compared to $50 \mu \mathrm{M}$ with $100 \mu \mathrm{M}$ fed eyes having less fused ommatidia (indicated by dotted circles) and $500 \mu \mathrm{M}$ feeding did not improve rectification of the eyes further. Thus, the optimum concentration for amelioration of the REP in GMR-A $\beta 42$ transgenic flies for DWE, SalA and SalB are $10 \mathrm{mg} / \mathrm{mL}, 100 \mu \mathrm{M}$ and $100 \mu \mathrm{M}$, respectively.

Scanning electron microscopy (SEM) was used to analyse the phenotype at higher magnification (Figure 5). GMR-A $\beta 42 . D M S O$ eyes (Figure 5B and 5B') showed merged and bulged ommatidia that had perforated holes which gave the eye a "glazed" exterior compared to GMR-OreR.DMSO's (Figure 5A) "egg-like" shaped eye. In addition, the overall interommatidial bristles were fewer than the Control and exhibited distorted polarities.

The extent of rescue effect on A 342 's toxicity was assessed using the Flynotyper software (Iyer et al., 2018, 2016). The quantification of morphological disfigurements in the Drosophila eye was evaluated in the form of the phenotypic score (P-score). The higher the $\mathrm{P}$-score, the more distorted that specific eye is, and thus the more severe the REP is (Figure 5F). Parallel to SEM images (Figures 5A-G and 5A'-G'), the P-score for GMR-A $\beta 42$.DMSO was significantly higher $(\mathrm{p}=0.0088)$ than GMR-OreR.DMSO, demonstrating A $\beta 42$ 's adverse effects on Drosophila eyes when not supplemented with any extra extracts or compounds. Feeding of DWE, SalA and SalB reduced the P-score on the eyes with GMR-A $\beta 42 . D W E$ having the lowest P-score among compound-fed Drosophila compared to GMRA $342 . D M S O ~(p=0.0028)$, followed by SalB $(p=0.0015)$ and SalA $(p=0.011)$. These results implied that DWE and its components SalA and SalB showed amelioration towards A $\beta 42-$ induced neurodegeneration in Drosophila in a dosage dependent manner, with $10 \mathrm{mg} / \mathrm{mL}$ DWE being the optimum dosage.

\section{DWE, SalA and SalB extended the lifespan of the Drosophila AD model}

The effect of prolonged exposure to $10 \mathrm{mg} / \mathrm{mL}$ DWE, $100 \mu \mathrm{M}$ SalA and $100 \mu \mathrm{M}$ SalB and their influence on longevity were investigated. In order to do this, the Actin5CGAL4 driver which drives ubiquitous expression in muscle tissue was employed. There was no significant difference when Actin5C-OreR Drosophila was fed with DWE, SalA and SalB versus the same line cultured with only vehicle control (0.5\% DMSO) for both males (Table 2, Figure 6A) and females (Table 3, Figure 6C). This indicated that DWE and its compounds did not exert any ill effects on the lifespan of control Drosophila. On the other hand, Actin5C-A 342 .DMSO Drosophila was significantly different from Actin5C-OreR.DMSO with average median lifespans of male and female dropping by $42.8 \%$ and $47.6 \%$ respectively. Moreover, Actin5C-A $\beta 42$ Drosophila lines with DWE, SalA and SalB consumptions were significantly different compared to Actin5C-A $\beta 42$.DMSO. The average median lifespans for male A $\beta 42$-expressing Drosophila increased by $75 \%, 37.5 \%$ and $37.5 \%$ after feeding of $10 \mathrm{mg} / \mathrm{mL}$ DWE, $100 \mu \mathrm{M}$ SalA and $100 \mu \mathrm{M}$ SalB respectively when compared to vehicle control-fed Actin5C-A $\beta 42 . D M S O$ (Table 2, Figure 6B). Likewise, Actin5C-A 342 .DMSO females experienced $63.6 \%, 36.7 \%$ and $72.7 \%$ extension in average 
median lifespan after being cultured in $10 \mathrm{mg} / \mathrm{mL}$ DWE, $100 \mu \mathrm{M}$ SalA and $100 \mu \mathrm{M}$ SalB respectively (Table 2, Figure 6D).

To investigate the magnitude of rescue effect of the compounds, comparison of the ratio of Actin5C-A $\beta 42$.compound:Actin5C-A $\beta 42$.DMSO was made. As the same Actin5CA $\beta 42$.DMSO triplicate line was utilized to compare all of the compound-fed fly lines, the length of lifespan for Actin5C-A $\beta 42 . D M S O$ remained static. The determining element depended on the lifespan length of compound-fed lines. Longer lifespans of compound-fed fly lines resulted in higher ratio values which indicated the compounds had a higher potency in prolonging lifespan. Based on the males, the ratios of Actin5C-A $342 . D W E$ :Actin5CA 342 .DMSO for the restricted mean and average maximum lifespan were 1.75 and 1.74, respectively. For SalA, the ratios were 1.39 and 1.84, respectively while SalB males had ratios of 1.51 and 2.00, respectively. On the other hand, DWE females exhibited ratios of 1.64 and 1.57, respectively. Females of SalA had ratios of 1.40 and 1.48, respectively while SalB females showed ratios of 1.73 and 1.90. Here, we showed that DWE, SalA and SalB were able to prolong Actin5C-A $\beta 42$ Drosophila's severely shortened lifespan. When compared within sexes, DWE was the most effective in lengthening the lifespan of male Actin5C-A $\beta 42$ Drosophila, followed by SalB and SalA. Alternatively, female Actin5C-A $\beta 42$ Drosophila benefit most from SalB consumption followed by DWE and finally SalA.

\section{Increased average climbing speed $(\mathrm{mm} / \mathrm{s})$ in compound-fed AD Drosophila}

In Drosophila, accumulation of A $\beta 42$ peptides contributes to locomotor dysfunction (Iijima et al., 2004). Hence, the possibility of these compounds having significant effects on the mobility of the AD Drosophila was investigated. In this experiment, Actin5C-A $\beta 42$ Drosophila were cultured with and without compounds (DWE, SalA and SalB) and the negative geotaxis assay was performed. This assay recorded the average climbing speed $(\mathrm{mm} / \mathrm{s})$ of the flies.

For male AD Drosophila fed with and without DWE (Figure 7A), there was a significant difference in the average climbing speed between Actin5C-A $\beta 42 . D W E$ and Actin5C-A $342 . D M S O$. Actin5C-A $342 . D W E$ had a higher average climbing speed than Actin5C-A 342 .DMSO at all three time points. Similar to the males, there was a significant difference in the average climbing speed of female Actin5C-A $\beta 42$.DWE and Actin5CA $\beta 42 . D M S O$ (Figure 7B). Actin5C-A $\beta 42$.DWE showed higher average climbing speed than Actin5C-A $342 . D M S O$ at all three time points.

For male AD Drosophila fed with and without SalA (Figure 7C), the male Actin5CA $\beta 42$.SalA showed significantly higher average climbing speed compared to Actin5C$\mathrm{A} \beta 42 . \mathrm{DMSO}$ at all three timepoints. Contrary to the male Actin5C-A $\beta 42$.SalA (Figure 7D), female Actin5C-A $\beta 42$.SalA showed no significant difference in average climbing speed between Actin5C-A $\beta 42$.SalA and Actin5C-A $\beta 42 . D M S O$ for all three time points.

For male AD Drosophila fed with and without SalB (Figure 7E), there was a significant difference between the Actin5C-A $\beta 42$.SalB and Actin5C-A $\beta 42 . D M S O$ for all three time points. Female Actin5C-A $\beta 42$.SalB (Figure 7F) was also shown to have significant difference in average climbing speed when compared to Actin5C-A $\beta 42$.DMSO but only on the $10^{\text {th }}$ and $15^{\text {th }}$ day.

To study the extent of rescue effect of the compounds, we compared the ratio between the average speed of AD Drosophila fed with and without the compounds, whereby a higher 
ratio indicates a better effect on the mobility. It was suggested that SalB had the best effect for male AD Drosophila. For the female counterpart, DWE had the best effect on all three time points, suggesting it to be the best compound even at an early stage.

\section{Discussion}

With respect to the $\mathrm{AD}$ amyloidogenesis pathogenesis, neurotoxic amyloid plaques found in the brains of AD patients comprised primarily of a 40-42 amyloid-beta (A $\beta$ ) amino acid with A $\beta 42$ being the most fibrillary species (Götz et al., 2011). The Chinese sage, Danshen has been employed throughout traditional Chinese medicinal history as a therapeutic agent for various cardiovascular and cerebrovascular diseases. This study takes advantage of Danshen's vast beneficial properties aiming to uncover a potential remedy for Alzheimer's disease. Here, Danshen and its water-soluble components SalA and SalB on A $\beta 42$ were tested both in in vitro and in a model organism.

We first verified that DWE, SalA and SalB possessed the ability to reduce fibrillation rate of $A \beta 42$ using the $A \beta 42$ aggregation assay. SalA was found to be the most proficient inhibitor followed by SalB and lastly DWE. Indeed, SalA's addition to A $\beta 42$ peptides not only yielded lowered RFU readings but also led to decreasing RFU intensities from the $900^{\text {th }}$ second. This could be due to its potential ability to revert the A $\beta 42$ fibrils to their monomeric form. This was supported by previous work that exhibited the propensity of SalA to disaggregate pre-formed A $\beta 42$ fibrils (Cao et al., 2013).

Next, the ability of these inhibitors to exert neuroprotective effect on cells in a controlled-setting was investigated. The pheochromocytoma PC12 cells obtained from rat adrenal medulla were chosen for their extremely high sensitivity to A $\beta$-associated neurodegeneration, a response higher than the human cell line, SH-SY5Y (Sakagami et al., 2017, 2018). When tested on the PC12 cells, SalB was most efficient in protecting PC12 cells against A $\beta 42$ 's neurotoxicity, followed by SalA and DWE. A key basis for the formation and stability of $A \beta$ fibrils is the fitting and stacking of aromatic rings between the peptides that provide strong $\pi-\pi$ interactions, thus stabilizing the complex (Chini et al., 2009; Makin et al., 2005). DWE contains a high amount of polyphenols with SalA and SalB being the most abundant. Polyphenols have been shown to weaken the aromatic links between A $\beta$ fibrils (Porat et al., 2006). However, DWE was the least effective inhibitor in this assay which could be attributed to it being a crude extract consisting of various components that might block the binding of polyphenols available in the extract when tested in an in vitro environment. In contrast, compounds SalA and SalB were over $98 \%$ pure.

Subsequent experiments were carried out with live organisms. Prior to behavioural studies, investigations on whether SalA and SalB were digested by the Drosophila as well as determination of the parts of the body that the compounds were transported to were performed. It was observed that while most of both compounds were expelled out of the Drosophila, there were small amounts detected in the bodies and heads. This showed the possibility that there was a transfer of both compounds to the brain after the feeding of DWE. It also raised the likelihood that SalA and SalB were utilized by neurons in live organisms. However, there were undetectable levels of SalA and SalB in the heads, bodies and faeces which could be due to their short half-life (Pei et al., 2008, Y. T. Wu et al., 2006).

The neurotoxicity assay that uses the eye structures of the Drosophila showed that DWE was the most effective treatment against A $\beta 42$-induced REP followed by SalB and SalA. The longevity assay exhibited similar results with slight variations between genders. SalB worked best for females followed by DWE and SalA. In in vitro condition, SalA was 
the best inhibitor of $A \beta 42$ aggregation. However, it provided the least protection when fed to a whole organism and this could be due to its incomplete cellular absorption compared to SalB. This difference in absorption was previously demonstrated in rats whereby oral administration of SalA showed a significantly lower plasma concentration of only $308 \mathrm{ng} / \mathrm{ml}$ compared to SalB which reached $1.5 \mu \mathrm{g} / \mathrm{ml}$ (Y. T. Wu et al., 2006, Pei et al., 2008). The UPLC findings from this study further supported this claim with the concentration of SalB found in the brains of DWE-fed flies being three times more than that of SalA.

The negative geotaxis assay to assess mobility recovery suggested that the compounds have a rescue effect on most of the AD Drosophila with the exception of females fed with SalA. While the exact mechanism is still unknown, this protective effect could be due to the antioxidative properties of the compounds as PC12 cells were extremely receptive to changes in oxygen levels (Alvarez-Tejado et al., 2001). It was shown by Li et al., (2008) that there was an elevated amount of reactive oxygen species/reactive nitrogen species (ROS/RNS) which preceded mitochondrial dysfunction, apoptosis and cell death when PC12 cells were exposed to A $\beta$ (Guo et al., 2013). Mitochondrial damage prompted the loss of ATP (Li et al., 2008; Moreira et al., 2010, Chong et al., 2019) and resulted in a surge in ROS, further causing apoptotic cell death (Chong et al., 2019). In previous studies, salvianolic acids including SalA and SalB have been shown to inhibit the production of ROS in experimental stroke (Lv et al., 2015) and liver injury (Z. Wu et al., 2007) in rats. As such, this antioxidative mechanism of DWE and its polyphenol components might be functioning similarly for A $\beta$ incubated PC12 cells and AD Drosophila.

\section{Conclusion}

DWE as a whole was able to rescue AD phenotypes in a sex-dependent manner when introduced to AD Drosophila. This is the first study at the time of writing that employed Drosophila melanogaster to study the neuroprotective effects of DWE and its components SalA and SalB on neuro-diseases, specifically AD. It is hoped that these discoveries will generate further queries into the fundamental aspects of the protective abilities of the extract and its compounds and thereby assist in the prevention of neuro-diseases in human.

\section{Acknowledgements}

We would like to thank all our collaborators and colleagues for the discussion and the work conducted in this lab. We would also like to extend our gratitude to Emiko Sanada, Tatsuro Kawamura and Kaori Honda of RIKEN CSRS for their assistance in the project. This study was funded by the USM Top Down Research Fund - URICAS (1001/PBIOLOGI/870029). Florence Hui Ping Tan is the recipient of the MyBrainSc scholarship and RIKEN International Program Associate.

\section{References}

Ai, C.-B., \& Li, L.-N. (1988). Stereostructure of Salvianolic Acid B and Isolation of Salvianolic Acid C from Salvia miltiorrhiza. Journal of Natural Products, 51(1), 145149. https://doi.org/10.1021/np50055a023

Alvarez-Tejado, M., Naranjo-Suárez, S., Jiménez, C., Carrera, A. C., Landázuri, M. O., \& del Peso, L. (2001). Hypoxia Induces the Activation of the Phosphatidylinositol 3Kinase/Akt Cell Survival Pathway in PC12 Cells. Journal of Biological Chemistry, 
bioRxiv preprint doi: https://doi org/10.1101/2020.05.12.089797; this version posted May 14,2020 . The copyright holder for this preprint (which was not certified by peer review) is the author/funder, who has granted bioRxiv a license to display the preprint in perpetuity. It is made available under aCC-BY-NC-ND 4.0 International license.

276(25), 22368-22374. https://doi.org/10.1074/jbc.M011688200

Basler, K., Christen, B., \& Hafen, E. (1991). Ligand-independent activation of the sevenless receptor tyrosine kinase changes the fate of cells in the developing Drosophila eye. Cell, 64(6), 1069-1081. https://doi.org/10.1016/0092-8674(91)90262-W

Cagan, R. (2009). Chapter 5 Principles of Drosophila Eye Differentiation. Current Topics in Developmental Biology. https://doi.org/10.1016/S0070-2153(09)89005-4

Cagan, R. L., \& Ready, D. F. (1989). The emergence of order in the Drosophila pupal retina. Developmental Biology, 136(2), 346-362. https://doi.org/10.1016/0012-1606(89)902613

Cao, Y. Y., Wang, L., Ge, H., Lu, X. L., Pei, Z., Gu, Q., \& Xu, J. (2013). Salvianolic acid A, a polyphenolic derivative from Salvia miltiorrhiza bunge, as a multifunctional agent for the treatment of Alzheimer's disease. Molecular Diversity, 17(3), 515-524. https://doi.org/10.1007/s11030-013-9452-z

Chen, X., Guo, J., Bao, J., Lu, J., \& Wang, Y. (2014). The Anticancer Properties of Salvia Miltiorrhiza Bunge (Danshen): A Systematic Review. Medicinal Research Reviews, 34(4), 768-794. https://doi.org/10.1002/med.21304

Chini, M. G., Scrima, M., D’Ursi, A. M., \& Bifulco, G. (2009). Fibril aggregation inhibitory activity of the $\beta$-sheet breaker peptides: A molecular docking approach. Journal of Peptide Science. https://doi.org/10.1002/psc.1095

Chong, C.-M., Su, H., Lu, J.-J., \& Wang, Y. (2019). The effects of bioactive components from the rhizome of Salvia miltiorrhiza (Danshen) on the characteristics of Alzheimer's disease. Chinese Medicine, 14(1), 19. https://doi.org/10.1186/s13020-019-0242-0

Ferri, C. P., Prince, M., Brayne, C., Brodaty, H., Fratiglioni, L., Ganguli, M., ... Scazufca, M. (2005). Global prevalence of dementia: A Delphi consensus study. Lancet. https://doi.org/10.1016/S0140-6736(05)67889-0

Finelli, A., Kelkar, A., Song, H.-J., Yang, H., \& Konsolaki, M. (2004). A model for studying Alzheimer's A $\beta 42$-induced toxicity in Drosophila melanogaster. Molecular and Cellular Neuroscience, 26(3), 365-375. https://doi.org/10.1016/j.mcn.2004.03.001

Götz, J., Eckert, A., Matamales, M., Ittner, L. M., \& Liu, X. (2011). Modes of A $\beta$ toxicity in Alzheimer's disease. Cellular and Molecular Life Sciences. https://doi.org/10.1007/s00018-011-0750-2

Groenning, M. (2010). Binding mode of Thioflavin T and other molecular probes in the context of amyloid fibrils - current status. Journal of Chemical Biology, 3(1), 1-18. https://doi.org/10.1007/s12154-009-0027-5

Guo, C., Sun, L., Chen, X., \& Zhang, D. (2013). Oxidative stress, mitochondrial damage and neurodegenerative diseases. Neural Regeneration Research, 8(21), 2003-2014. https://doi.org/10.3969/j.issn.1673-5374.2013.21.009

Helfand, S. L., \& Rogina, B. (2003). Genetics of Aging in the Fruit Fly, Drosophila melanogaster. Annual Review of Genetics, 37(1), 329-348. https://doi.org/10.1146/annurev.genet.37.040103.095211

Hügel, H. M., \& Jackson, N. (2014). Danshen diversity defeating dementia. Bioorganic \& Medicinal Chemistry Letters, 24(3), 708-716. 
https://doi.org/10.1016/j.bmcl.2013.12.042

Hung, C.-W., Chen, Y.-C., Hsieh, W.-L., Chiou, S.-H., \& Kao, C.-L. (2010). Ageing and neurodegenerative diseases. Ageing Research Reviews, 9, S36-S46. https://doi.org/10.1016/j.arr.2010.08.006

Iijima, K., Liu, H. P., Chiang, A. S., Hearn, S. A., Konsolaki, M., \& Zhong, Y. (2004). Dissecting the pathological effects of human A $\beta 40$ and $A \beta 42$ in Drosophila: A potential model for Alzheimer's disease. Proceedings of the National Academy of Sciences of the United States of America, 101(17), 6623-6628. https://doi.org/10.1073/pnas.0400895101

Ittner, L. M., \& Götz, J. (2011). Amyloid- $\beta$ and tau - a toxic pas de deux in Alzheimer's disease. Nature Reviews Neuroscience, 12(2), 67-72. https://doi.org/10.1038/nrn2967

Iyer, J., Singh, M. D., Jensen, M., Patel, P., Pizzo, L., Huber, E., ... Girirajan, S. (2018). Pervasive genetic interactions modulate neurodevelopmental defects of the autismassociated 16p11.2 deletion in Drosophila melanogaster. Nature Communications, 9(1), 2548. https://doi.org/10.1038/s41467-018-04882-6

Iyer, J., Wang, Q., Le, T., Pizzo, L., Grönke, S., Ambegaokar, S. S., ... Girirajan, S. (2016). Quantitative Assessment of Eye Phenotypes for Functional Genetic Studies Using Drosophila melanogaster. G3\&amp;\#58; Genes|Genomes|Genetics, 6(5), 1427-1437. https://doi.org/10.1534/g3.116.027060

Ja, W. W., Carvalho, G. B., Mak, E. M., de la Rosa, N. N., Fang, A. Y., Liong, J. C., ... Benzer, S. (2007). Prandiology of Drosophila and the CAFE assay. Proceedings of the National Academy of Sciences, 104(20), 8253-8256. https://doi.org/10.1073/pnas.0702726104

Jiang, R.-W., Lau, K.-M., Hon, P.-M., Mak, T., Woo, K.-S., \& Fung, K.-P. (2005). Chemistry and Biological Activities of Caffeic Acid Derivatives from Salvia miltiorrhiza. Current Medicinal Chemistry, 12(2), 237-246. https://doi.org/10.2174/0929867053363397

Kapoor, R., \& Kakkar, P. (2012). Protective Role of Morin, a Flavonoid, against High Glucose Induced Oxidative Stress Mediated Apoptosis in Primary Rat Hepatocytes. PLoS ONE, 7(8), e41663. https://doi.org/10.1371/journal.pone.0041663

Knopman, D. S. (2006). Current treatment of mild cognitive impairment and alzheimer's disease. Current Neurology and Neuroscience Reports, 6(5), 365-371. https://doi.org/10.1007/s11910-996-0016-9

Kumar, J. P. (2012). Building an ommatidium one cell at a time. Developmental Dynamics, 241(1), 136-149. https://doi.org/10.1002/dvdy.23707

Li, R. C., Pouranfar, F., Lee, S. K., Morris, M. W., Wang, Y., \& Gozal, D. (2008). Neuroglobin protects PC12 cells against $\beta$-amyloid-induced cell injury. Neurobiology of Aging, 29(12), 1815-1822. https://doi.org/10.1016/j.neurobiolaging.2007.05.001

Lian-niang, L., Rui, T., \& Wei-ming, C. (1984). Salvianolic Acid A, a New Depside from Roots of Salvia miltiorrhiza. Planta Medica, 50(03), 227-228. https://doi.org/10.1055/s2007-969684

Lv, H., Wang, L., Shen, J., Hao, S., Ming, A., Wang, X., ... Zhang, Z. (2015). Salvianolic acid B attenuates apoptosis and inflammation via SIRT1 activation in experimental stroke rats. Brain Research Bulletin, 115, 30-36. 
https://doi.org/10.1016/j.brainresbull.2015.05.002

Makin, O. S., Atkins, E., Sikorski, P., Johansson, J., \& Serpell, L. C. (2005). Molecular basis for amyloid fibril formation and stability. Proceedings of the National Academy of Sciences of the United States of America. https://doi.org/10.1073/pnas.0406847102

McGurk, L., Berson, A., \& Bonini, N. M. (2015). Drosophila as an In Vivo Model for Human Neurodegenerative Disease. Genetics, 201(2), 377-402. https://doi.org/10.1534/genetics.115.179457

Mei, X.-D., Cao, Y.-F., Che, Y.-Y., Li, J., Shang, Z.-P., Zhao, W.-J., ... Zhang, J.-Y. (2019). Danshen: a phytochemical and pharmacological overview. Chinese Journal of Natural Medicines, 17(1), 59-80. https://doi.org/10.1016/S1875-5364(19)30010-X

Moloney, A., Sattelle, D. B., Lomas, D. A., \& Crowther, D. C. (2010). Alzheimer's disease: insights from Drosophila melanogaster models. Trends in Biochemical Sciences, 35(4), 228-235. https://doi.org/10.1016/j.tibs.2009.11.004

Moreira, P. I., Carvalho, C., Zhu, X., Smith, M. A., \& Perry, G. (2010). Mitochondrial dysfunction is a trigger of Alzheimer's disease pathophysiology. Biochimica et Biophysica Acta (BBA) - Molecular Basis of Disease, 1802(1), 2-10. https://doi.org/10.1016/j.bbadis.2009.10.006

Moreira, P. I., Nunomura, A., Honda, K., Aliev, G., Casadenus, G., Zhu, X., . . Perry, G. (2007). The key role of oxidative stress in Alzheimer's disease. Oxidative stress and neurodegenerative disorders, 451, 466.

Murphy, M. P., \& LeVine, H. (2010). Alzheimer's Disease and the Amyloid- $\beta$ Peptide. Journal of Alzheimer's Disease, 19(1), 311-323. https://doi.org/10.3233/JAD-20101221

Pang, H., Wu, L., Tang, Y., Zhou, G., Qu, C., \& Duan, J. (2016). Chemical Analysis of the Herbal Medicine Salviae miltiorrhizae Radix et Rhizoma (Danshen). Molecules, 21(1), 51. https://doi.org/10.3390/molecules21010051

Pei, L., Bao, Y., Wang, H., Yang, F., Xu, B., Wang, S., ... Du, G. (2008). A sensitive method for determination of salvianolic acid $A$ in rat plasma using liquid chromatography/tandem mass spectrometry. Biomedical Chromatography, 22(7), 786794. https://doi.org/10.1002/bmc.1043

Porat, Y., Abramowitz, A., \& Gazit, E. (2006). Inhibition of Amyloid Fibril Formation by Polyphenols: Structural Similarity and Aromatic Interactions as a Common Inhibition Mechanism. Chemical Biology <html_ent Glyph="@amp;" Ascii="\&amp;"/>Drug Design, 67(1), 27-37. https://doi.org/10.1111/j.1747-0285.2005.00318.x

Rodriguez, A., Zhang, H., Klaminder, J., Brodin, T., \& Andersson, M. (2017). ToxId: an efficient algorithm to solve occlusions when tracking multiple animals. Scientific Reports, 7(1), 14774. https://doi.org/10.1038/s41598-017-15104-2

Rodriguez, A., Zhang, H., Klaminder, J., Brodin, T., Andersson, P. L., \& Andersson, M. (2018). ToxTrac: A fast and robust software for tracking organisms. Methods in Ecology and Evolution, 9(3), 460-464. https://doi.org/10.1111/2041-210X.12874

Sakagami, H., Suzuki, R., Shirataki, Y., Iwama, S., Nakagawa, M., Suzuki, H., ... Takeshima, H. (2017). Re-evaluation of Culture Condition of PC12 and SH-SY5Y Cells Based on Growth Rate and Amino Acid Consumption. In Vivo, 31(6), 1089-1095. 
https://doi.org/10.21873/invivo.11174

Sakagami, H., Tsuji, M., Tomomura, M., Masuda, Y., Iwama, S., Nakagawa, M., ... Oizumi, T. (2018). Protection of Differentiating Neuronal Cells from Amyloid $\beta$ Peptide-induced Injury by Alkaline Extract of Leaves of Sasa senanensis Rehder. In Vivo, 32(2), 231-239. https://doi.org/10.21873/invivo.11229

St Johnston, D. (2002). The art and design of genetic screens: Drosophila melanogaster. Nature Reviews Genetics, 3(3), 176-188. https://doi.org/10.1038/nrg751

Su, C.-Y., Ming, Q.-L., Rahman, K., Han, T., \& Qin, L.-P. (2015). Salvia miltiorrhiza: Traditional medicinal uses, chemistry, and pharmacology. Chinese Journal of Natural Medicines, 13(3), 163-182. https://doi.org/10.1016/S1875-5364(15)30002-9

Sun, Y., Yolitz, J., Wang, C., Spangler, E., Zhan, M., \& Zou, S. (2013). Aging Studies in Drosophila Melanogaster (T. O. Tollefsbol, Ed.). In (pp. 77-93). https://doi.org/10.1007/978-1-62703-556-9_7

Tan, F. H. P., \& Azzam, G. (2017). Drosophila melanogaster: Deciphering Alzheimer's Disease. Malaysian Journal of Medical Sciences, 24(2), 6-20. https://doi.org/10.21315/mjms2016.24.2.2

Tomlinson, A., Bowtell, D. D. L., Hafen, E., \& Rubin, G. M. (1987). Localization of the sevenless protein, a putative receptor for positional information, in the eye imaginal disc of Drosophila. Cell. https://doi.org/10.1016/0092-8674(87)90019-5

Wu, Y. T., Chen, Y. F., Hsieh, Y. J., Jaw, I., Shiao, M. S., \& Tsai, T. H. (2006). Bioavailability of salvianolic acid B in conscious and freely moving rats. International Journal of Pharmaceutics. https://doi.org/10.1016/j.ijpharm.2006.07.003

Wu, Z., Wen, T., Tan, Y., Liu, Y., Ren, F., \& Wu, H. (2007). Effects of Salvianolic Acid A on Oxidative Stress and Liver Injury Induced by Carbon Tetrachloride in Rats. Basic \& Clinical Pharmacology \& Toxicology, 100(2), 115-120. https://doi.org/10.1111/j.17427835.2007.00020.x

Zhou, L., Zuo, Z., \& Chow, M. S. S. (2005). Danshen: An Overview of Its Chemistry, Pharmacology, Pharmacokinetics, and Clinical Use. The Journal of Clinical Pharmacology, 45(12), 1345-1359. https://doi.org/10.1177/0091270005282630

\section{Supplementary Data}

The videos for the negative geotaxis assay can be downloaded from the link. The flies in each tube are in the order of (left to right): control (Actin5C-OreR.DMSO), AD Drosophila fed without compounds (Actin5C-A 342 .DMSO) and AD Drosophila fed with compounds

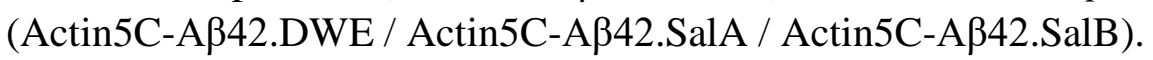

( https://drive.google.com/open?id=181bmDjS935dIHDtvSmIB7j13pjRcnWs2) 
bioRxiv preprint doi: https://doi.org/10.1101/2020.05.12.089797; this version posted May 14, 2020. The copyright holder for this preprint (which was not certified by peer review) is the author/funder, who has granted bioRxiv a license to display the preprint in perpetuity. It is made available under aCC-BY-NC-ND 4.0 International license.

\section{Graphical Abstract}

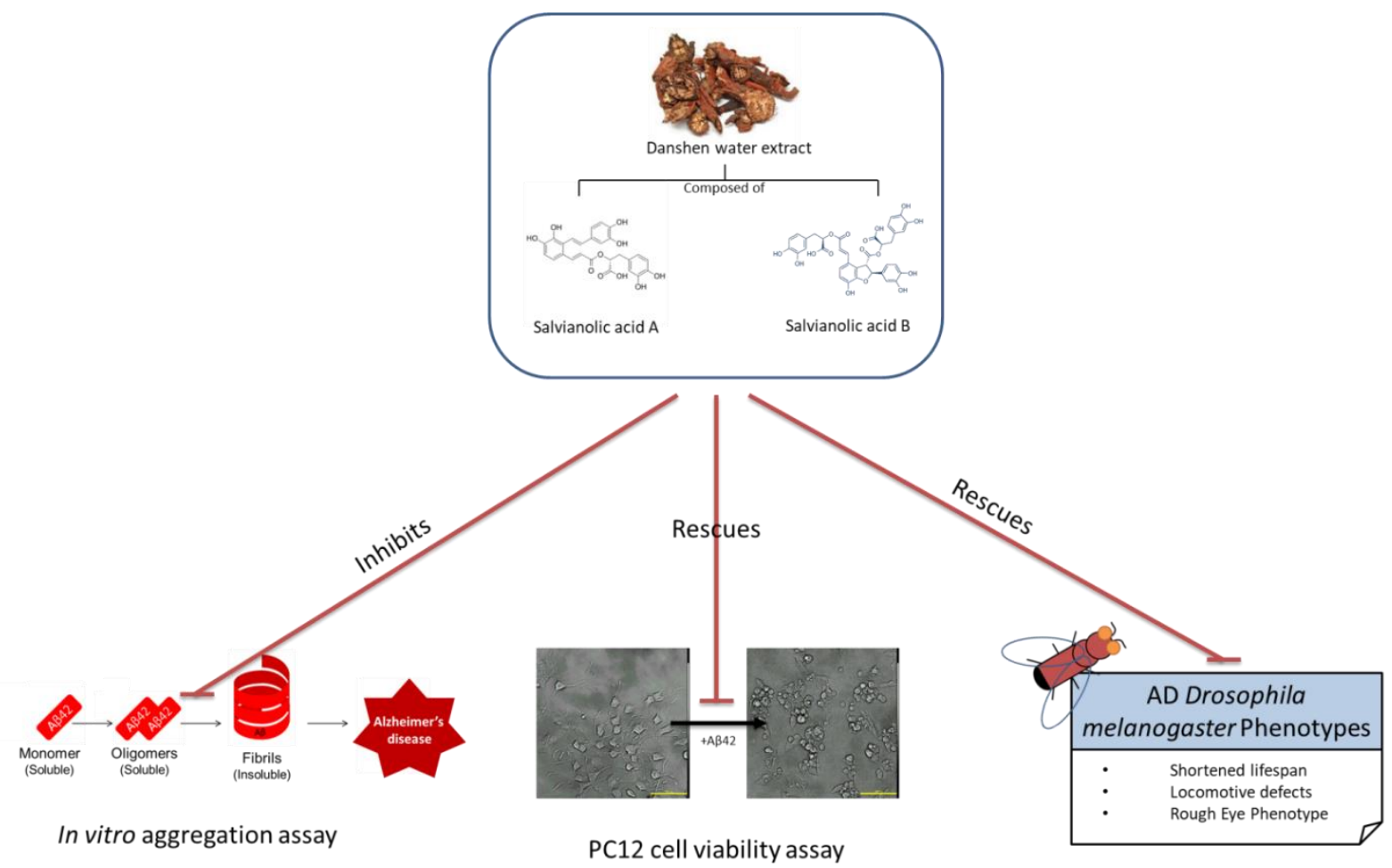


bioRxiv preprint doi: https://doi.org/10.1101/2020.05.12.089797; this version posted May 14, 2020. The copyright holder for this preprint (which was not certified by peer review) is the author/funder, who has granted bioRxiv a license to display the preprint in perpetuity. It is made available under aCC-BY-NC-ND 4.0 International license.

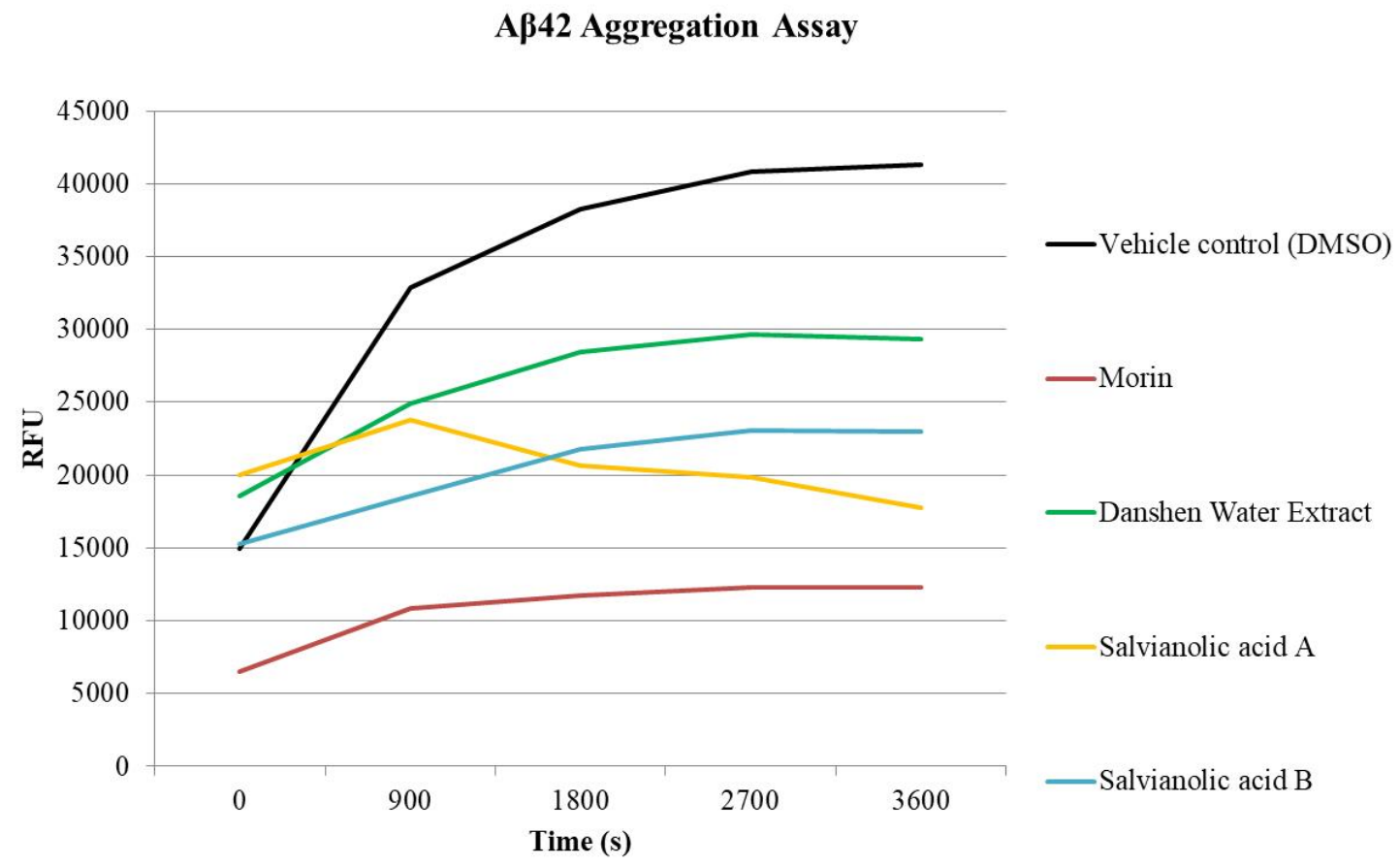

Figure 1: THT A 442 aggregation in vitro assay of DWE. 
bioRxiv preprint doi: https://doi org/10.1101/2020 05.12.089797; this version posted May 14 2020. The copyright holder for this preprint (which was not certified by peer review) is the author/funder, who has granted bioRxiv a license to display the preprint in perpetuity. It is made available under aCC-BY-NC-ND 4.0 International license.

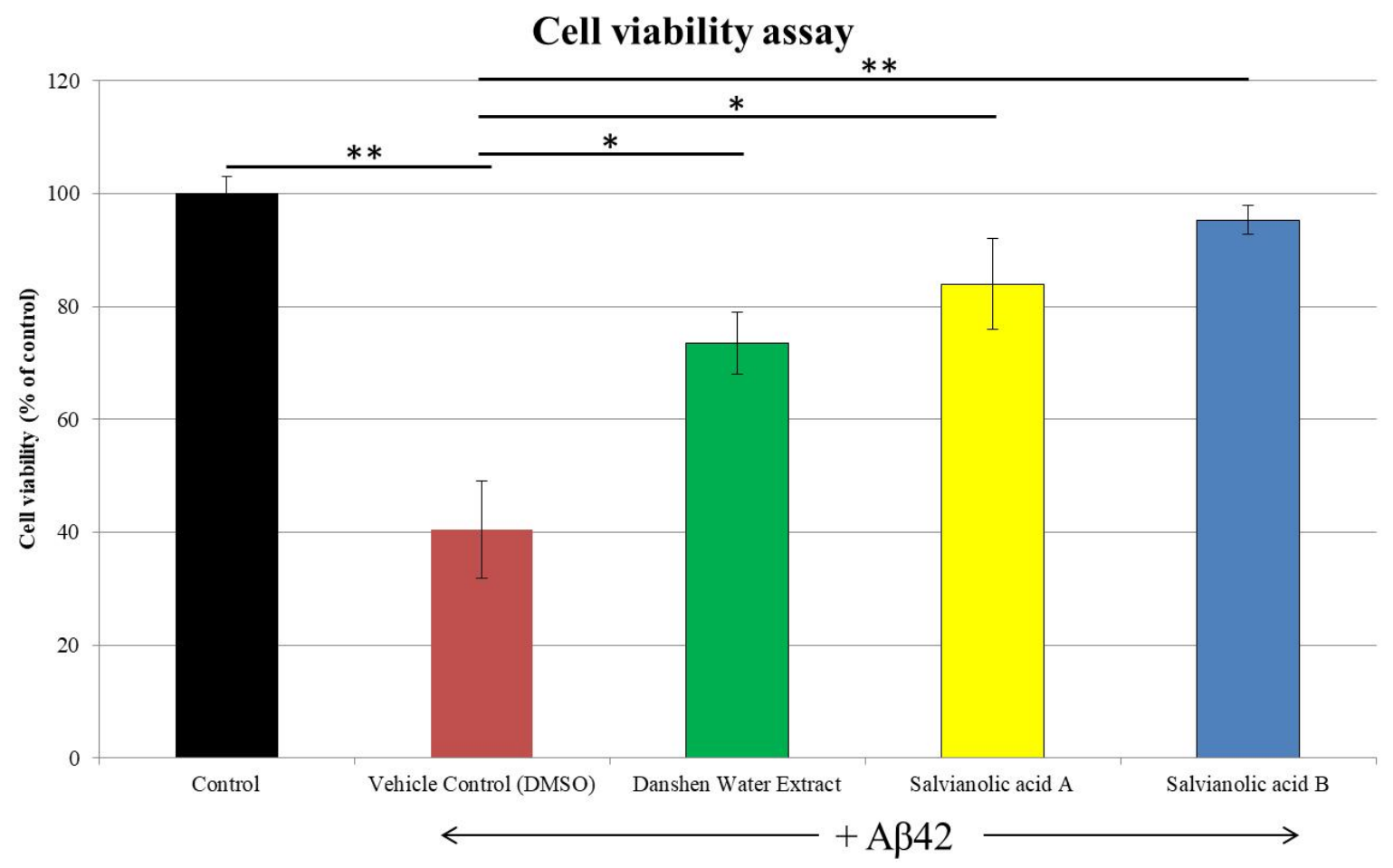

Figure 2: Cell viability assay of PC12 cells without addition of $\mathrm{A} \beta 42$ and compounds, and with addition of A $\beta 42$ supplemented with vehicle control ( $0.5 \%$ DMSO), SalA or SalB. $P$-values indicated significance at $* \mathrm{P}<0.05, * * \mathrm{P}<0.005$. 

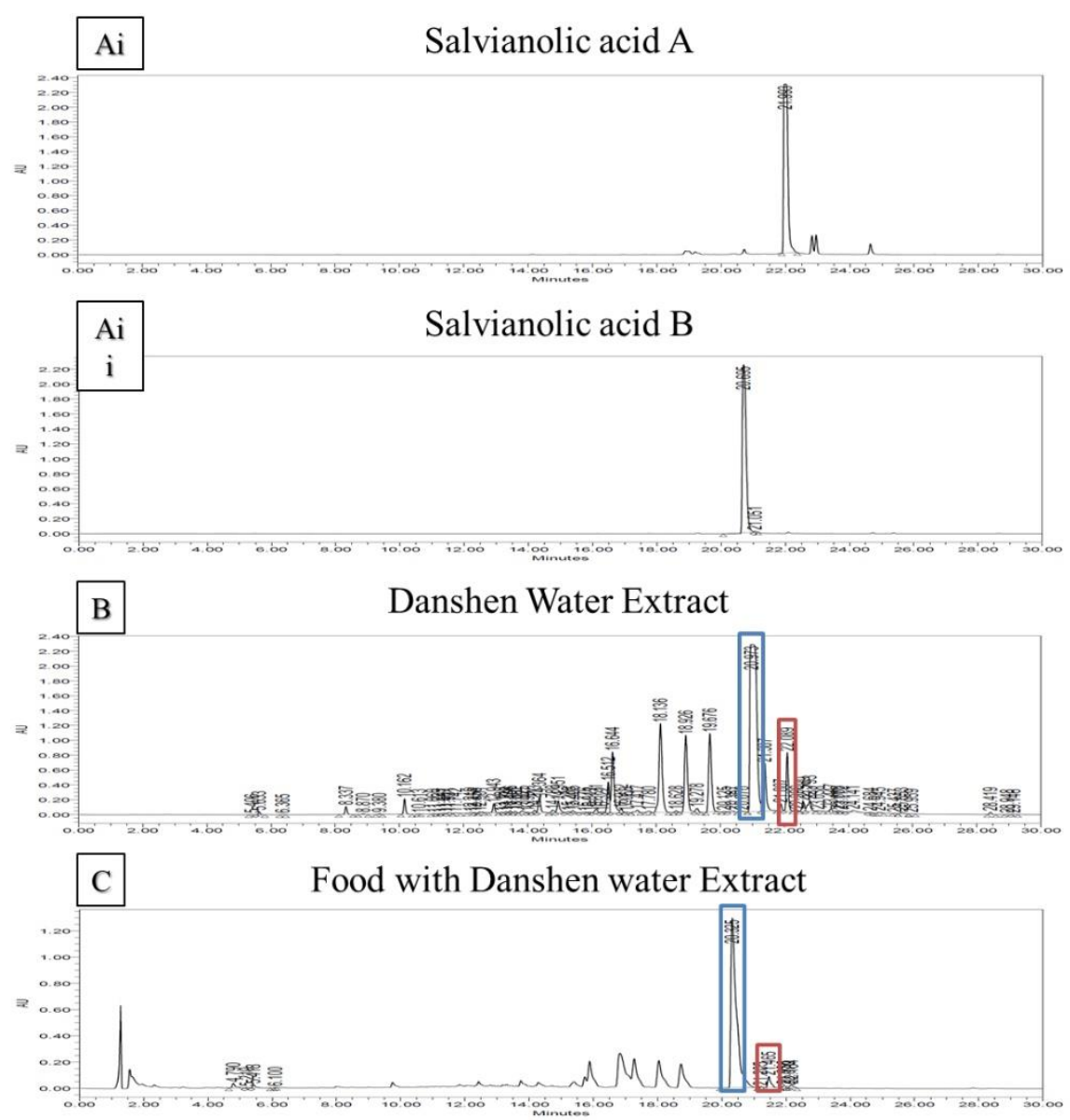

D Faeces after fed with Danshen water Extract

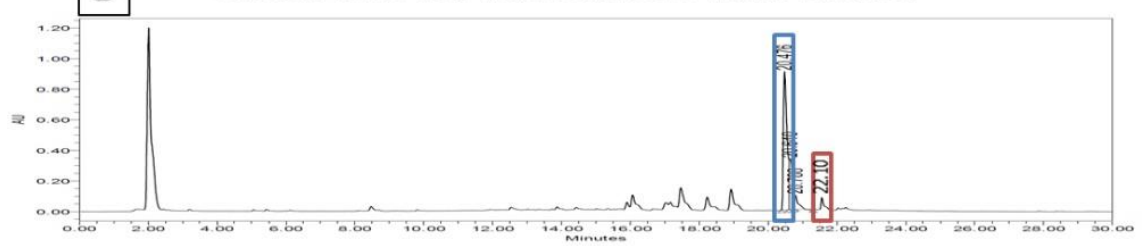

E Bodies fed with Danshen water Extract
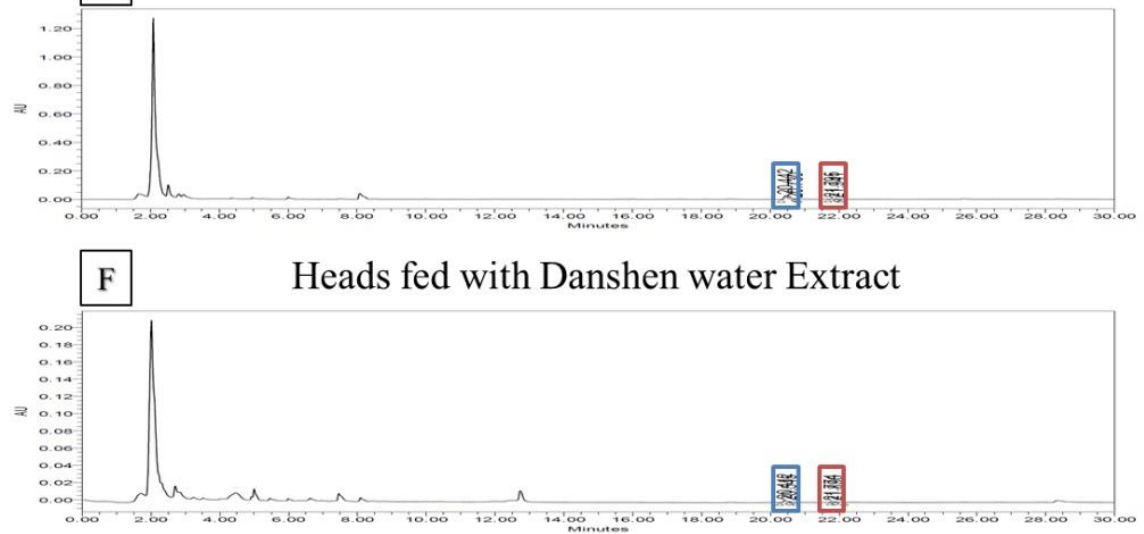

Figure 3: UPLC analysis of SalA and SalB. Ai and Aii depicts the standard graphs of pure SalA and SalB, respectively. B. shows the graph of DWE. C. shows the graph for food prepared with DWE while D. shows the graph of Drosophila faecal matter after fed food with DWE. E. and F. denote the graphs taken of the Drosophila bodies and heads, respectively after fed food with DWE. Blue boxes indicate SalB peaks while red boxes indicate SalA peaks. 

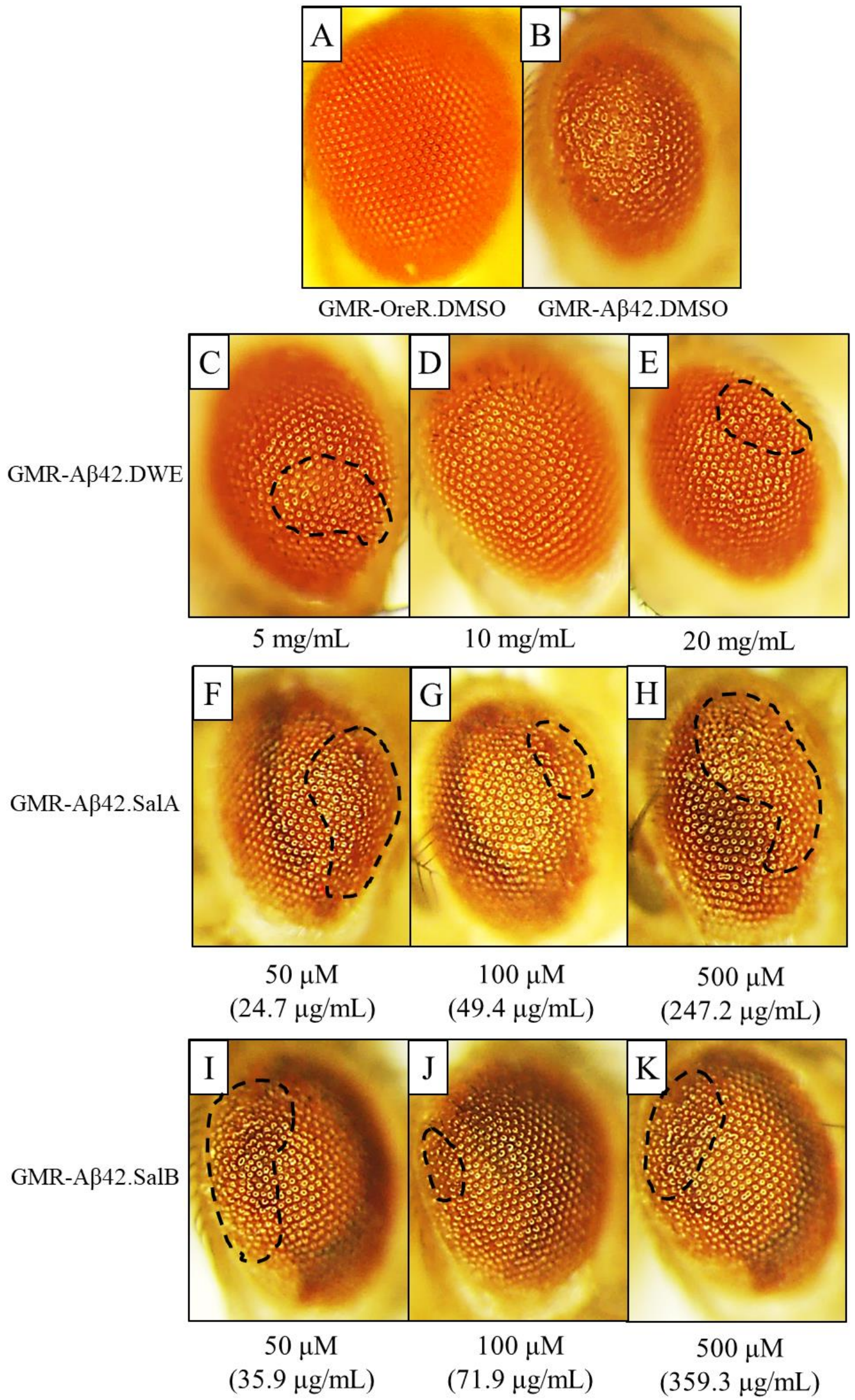
bioRxiv preprint doi: https://doi.org/10.1101/2020.05.12.089797; this version posted May 14, 2020. The copyright holder for this preprint (which was not certified by peer review) is the author/funder, who has granted bioRxiv a license to display the preprint in perpetuity. It is made available under aCC-BY-NC-ND 4.0 International license.

Figure 4: Light micrographs of transgenic Drosophila melanogaster eyes at magnifications x11.5. Black dotted circles indicate area with dense number of fused ommatidia. A. Eye of control GMROreR.DMSO. B. Eye of GMR-A $442 . D M S O$. C. to E. Eyes of GMR-A $342 . D W E$ Drosophila fed food with $5 \mathrm{mg} / \mathrm{mL}, 10 \mathrm{mg} / \mathrm{mL}$ and $20 \mathrm{mg} / \mathrm{mL}$ of DWE, respectively. F. to H. Eyes of GMR-A $\beta 42$.SalA Drosophila fed food with $50 \mu \mathrm{M}, 100 \mu \mathrm{M}$ and $500 \mu \mathrm{M}$ of SalA, respectively. I. to K. Eyes of GMRA 342 .SalB Drosophila fed food with $50 \mu \mathrm{M}, 100 \mu \mathrm{M}$ and $500 \mu \mathrm{M}$ of SalB, respectively. 
bioRxiv preprint doi: https://doi.org/10.1101/2020 05.12 089797: this version posted May 14,2020 . The copyright holder for this preprint (which was not certified by peer review) is the author/funder, who has granted bioRxiv a license to display the preprint in perpetuity. It is made available under aCC-BY-NC-ND 4.0 International license.

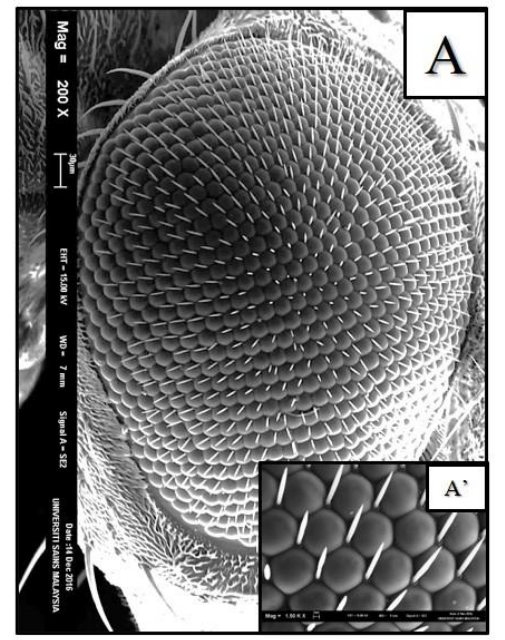

GMR-OreR.DMSO

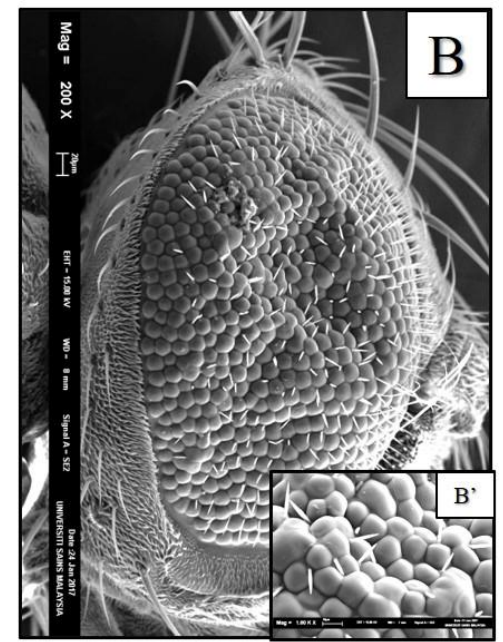

GMR-A $\beta 42 . D M S O$

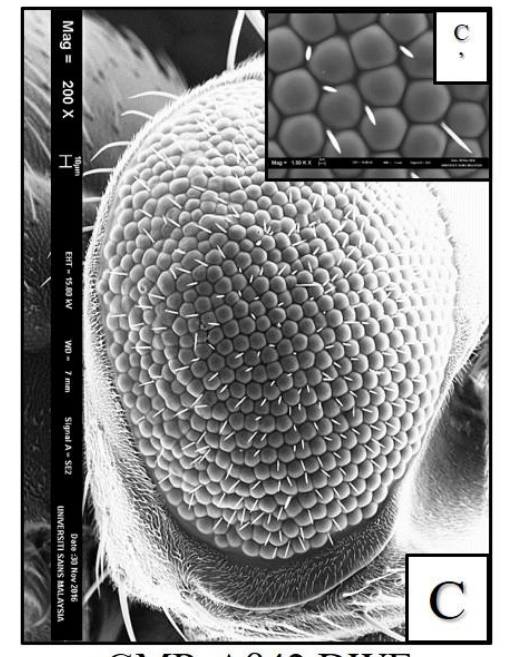

GMR-Aß42.DWE

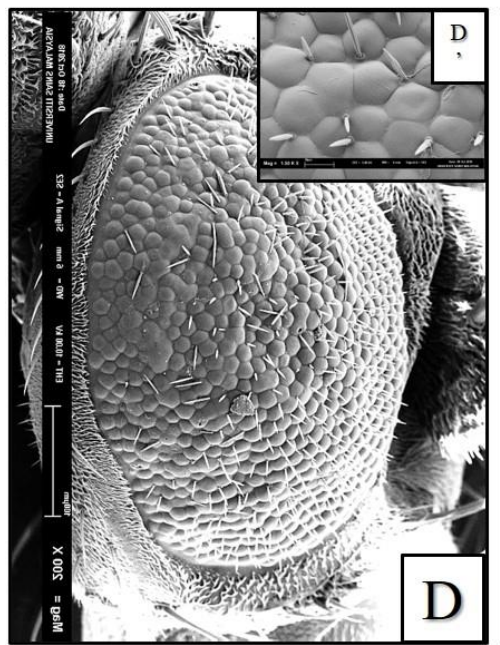

GMR-A $\beta 42$. SalA

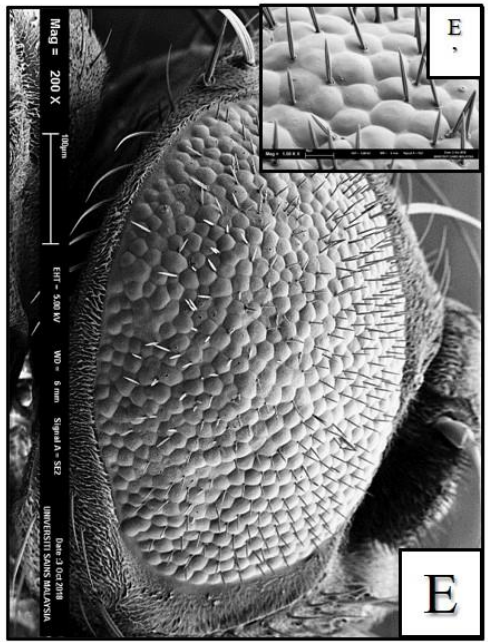

GMR-A $\beta 42 . S a l B$

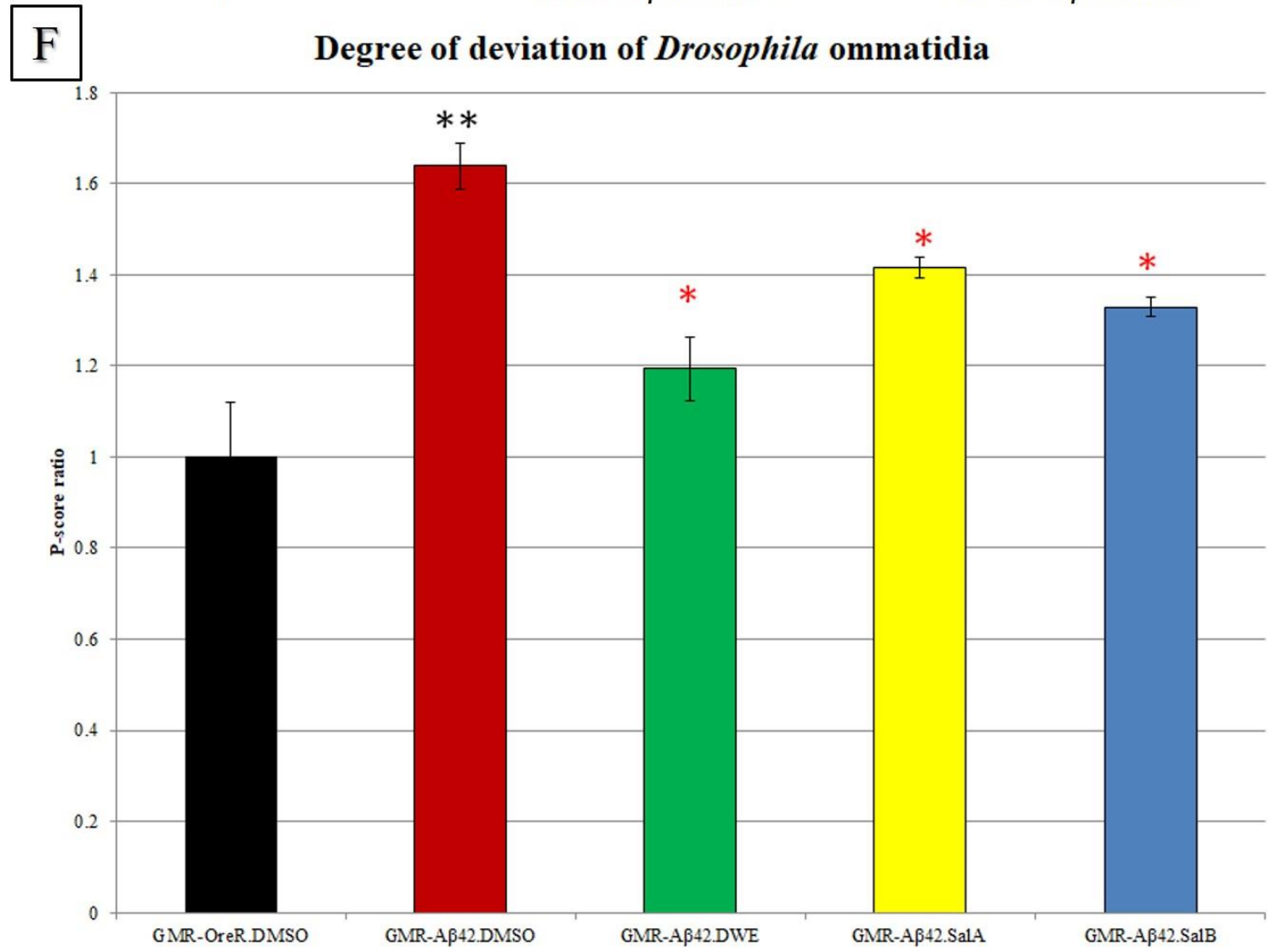


bioRxiv preprint doi: https://doi.org/10.1101/2020.05.12.089797; this version posted May 14, 2020. The copyright holder for this preprint (which was not certified by peer review) is the author/funder, who has granted bioRxiv a license to display the preprint in perpetuity. It is made available under aCC-BY-NC-ND 4.0 International license.

Figure 5: Scanning electron micrographs of transgenic Drosophila melanogaster at

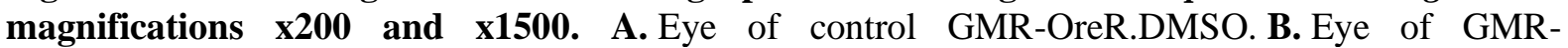
A 342 .DMSO. C. Eye of GMR-A 342 .DWE Drosophila fed food with $10 \mathrm{mg} / \mathrm{mL}$ of DWE. D. Eye of GMR-A 342.SalA Drosophila fed food with $100 \mu \mathrm{M}$ SalA. E. Eye of GMRA $\beta 42$. SalB Drosophila fed food with $100 \mu \mathrm{M}$ SalB. F. P-scores of the transgenic Drosophila melanogaster obtained from the Flynotyper software. $P$-values indicated significance at $* \mathrm{P}<0.05$. Black asterisk (*) represents P-values against the control while red asterisk (*) represents P-values against DMSO control 
Actin5C-OreR - Males
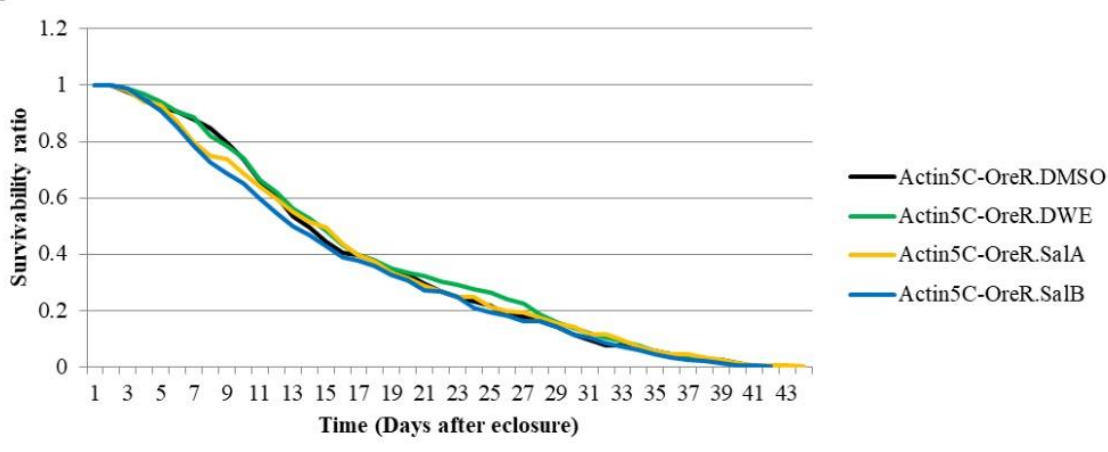

Actin5C-Aß42 - Males
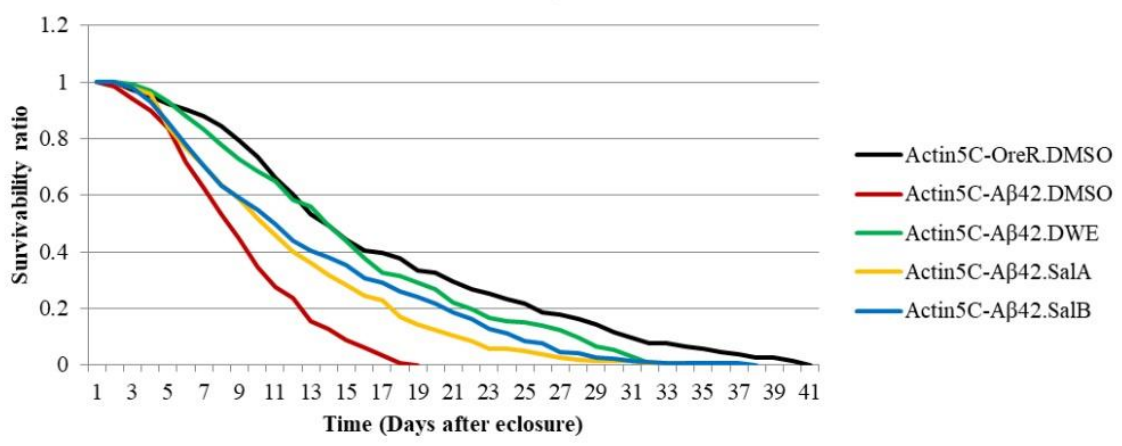

C

Actin5C-OreR - Females
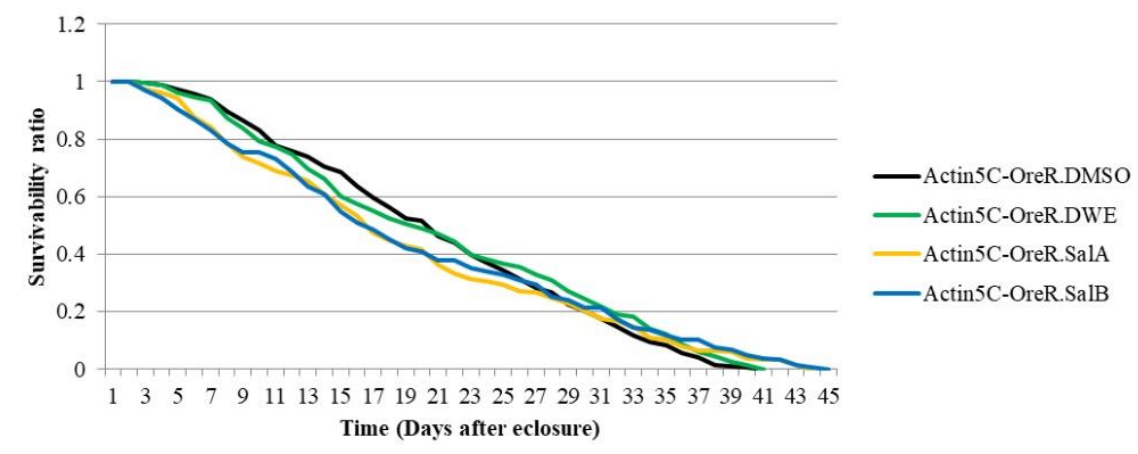

$\mathrm{D}$

Actin5C-Aß42 - Females

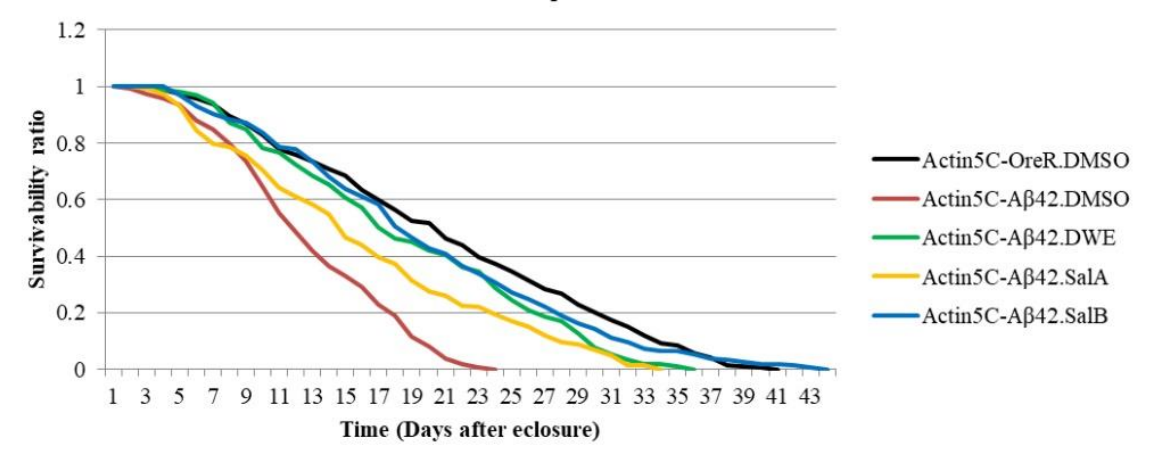

Figure 6: The effect of DWE on the lifespan of transgenic Drosophila melanogaster. A. and B. show the longevity graphs of Actin5C-OreR males and females, respectively. C. and D. depict the graphs of Actin5C-A $\beta 42$ males and females, respectively. 


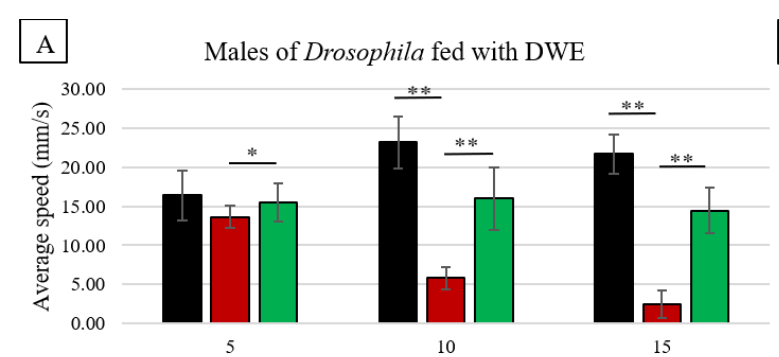

Time (days after enclosure)

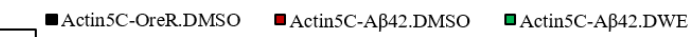
C Males of Drosophila fed with SalA

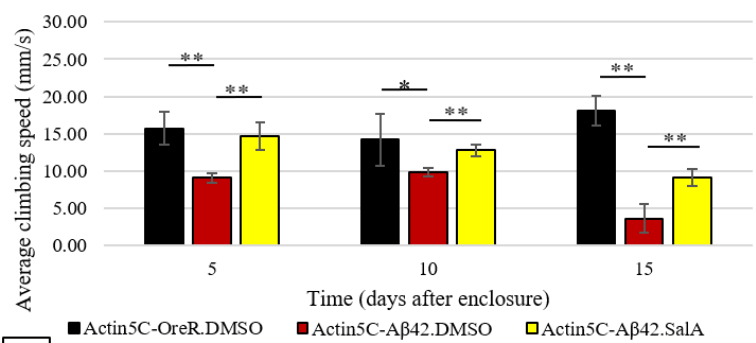

$\mathrm{E}$
Males of Drosophila fed with SalB

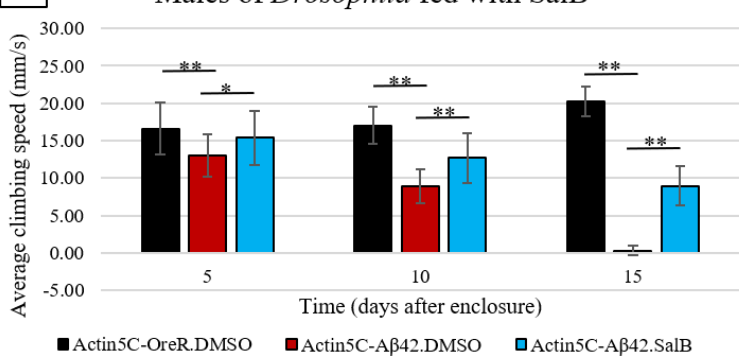

B Females of Drosophila fed with DWE

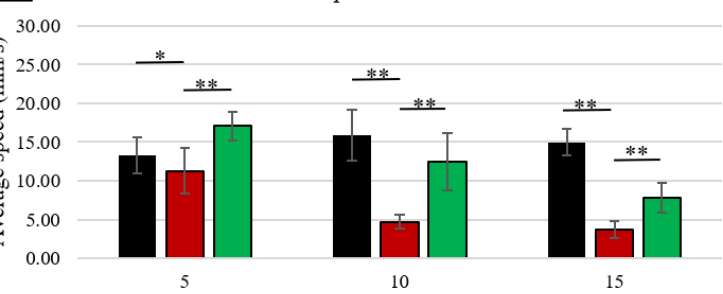

Time (days after enclosure)

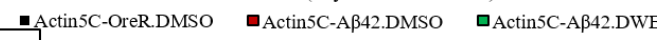

D Females of Drosophila fed with SalA

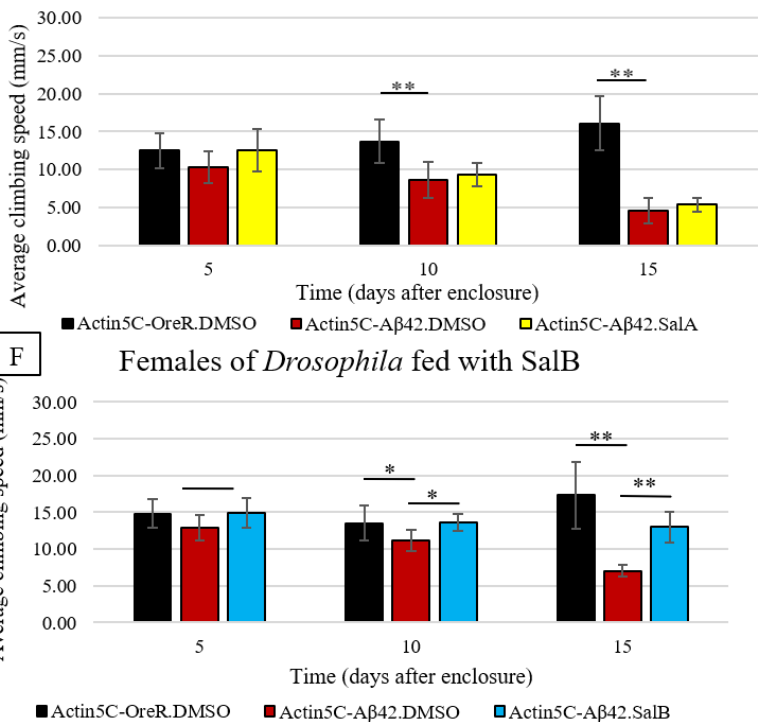

Figure 7. Average climbing speed $(\mathrm{mm} / \mathrm{s})$ of AD Drosophila fed with and without compounds at three time points ( 5 days, 10 days and 15 days). A. and B. show the average climbing speed of AD Drosophila fed with and without DWE. C. and D. show the average climbing speed of AD Drosophila fed with and without SalA. E. and F. show the average climbing speed of AD Drosophila fed with and without SalB. $P$-values indicated significance at $* \mathrm{P}<0.05$ and $* * \mathrm{P}<0.01$. 
bioRxiv preprint doi: https://doi org/10.1101/2020.05.12.089797; this version posted May 14,2020 . The copyright holder for this preprin (which was not certified by peer review) is the author/funder, who has granted bioRxiv a license to display the preprint in perpetuity. It is made available under aCC-BY-NC-ND 4.0 International license.

Table 1: List of Drosophila lines used in corresponding studies

\begin{tabular}{llll}
\hline Analysis used in & Drosophila line name & Compound fed & Abbreviation \\
\hline REP analysis & GMR-Oregon R & Vehicle control (DMSO) & GMR-OreR.DMSO \\
REP analysis & GMR-Oregon R & DWE & GMR-OreR.DWE \\
REP analysis & GMR-A $\beta 42$ & Vehicle control (DMSO) & GMR-A $\beta 42 . D M S O$ \\
REP analysis & GMR-A $\beta 42$ & DWE & GMR-A $\beta 42 . D W E$ \\
REP analysis & GMR-A $\beta 42$ & SalA & GMR-A $\beta 42 . S a l A$ \\
REP analysis & GMR-A $\beta 42$ & SalB & GMR-A $\beta 42 . S a l B$ \\
Longevity and Climbing analysis & Actin5C-Oregon R & Vehicle control (DMSO) & Actin5C-OreR.DMSO \\
Longevity and Climbing analysis & Actin5C-Oregon R & DWE & Actin5C-OreR.DWE \\
Longevity and Climbing analysis & Actin5C-Oregon R & SalA & Actin5C-OreR.SalA \\
Longevity and Climbing analysis & Actin5C-Oregon R & SalB & Actin5C-OreR.SalB \\
Longevity and Climbing analysis & Actin5C-A $\beta 42$ & Vehicle control (DMSO) & Actin5C-A $\beta 42 . D M S O$ \\
Longevity and Climbing analysis & Actin5C-A $\beta 42$ & DWE & Actin5C-A $\beta 42 . D W E$ \\
Longevity and Climbing analysis & Actin5C-A $\beta 42$ & SalA & Actin5C-A $\beta 42 . S a l A$ \\
Longevity and Climbing analysis & Actin5C-A $\beta 42$ & SalB & Actin5C-A $\beta 42 . S a l B$ \\
\hline
\end{tabular}

Table 2: Mean and median of male experimented Drosophila melanogaster lines fed with or without DWE, SalA or SalB

\begin{tabular}{|c|c|c|c|c|c|c|c|c|c|c|}
\hline \multirow[b]{2}{*}{ Name } & \multirow[b]{2}{*}{$\begin{array}{l}\text { No. of } \\
\text { subjects }\end{array}$} & \multicolumn{3}{|c|}{ Restricted mean } & \multicolumn{6}{|c|}{ Age in days at $\%$ mortality } \\
\hline & & Days & $\begin{array}{l}\text { Std. } \\
\text { error }\end{array}$ & $\begin{array}{l}95 \% \\
\text { C.I. }\end{array}$ & $25 \%$ & $50 \%$ & $75 \%$ & $90 \%$ & $100 \%$ & $\begin{array}{l}95 \% \\
\text { Median } \\
\text { C.I. }\end{array}$ \\
\hline $\begin{array}{r}\text { Actin5C- } \\
\text { OreR.DMSO }\end{array}$ & 156 & 17.14 & 0.76 & $\begin{array}{c}15.65 \sim \\
18.63\end{array}$ & 10 & 14 & 24 & 31 & 41 & $\begin{array}{l}13.0 \sim \\
15.0\end{array}$ \\
\hline $\begin{array}{l}\text { Actin5C- } \\
\text { OreR.DWE }\end{array}$ & 182 & 17.77 & 0.73 & $\begin{array}{c}16.35 \sim \\
19.19\end{array}$ & 10 & 15 & 26 & 33 & 41 & $\begin{array}{l}13.0 \sim \\
16.0\end{array}$ \\
\hline $\begin{array}{l}\text { Actin5C- } \\
\text { OreR.SalA }\end{array}$ & 156 & 17.14 & 0.76 & $\begin{array}{c}15.65 \sim \\
18.63\end{array}$ & 10 & 14 & 24 & 31 & 41 & $\begin{array}{l}13.0 \sim \\
15.0\end{array}$ \\
\hline $\begin{array}{c}\text { Actin5C- } \\
\text { OreR.SalB }\end{array}$ & 154 & 16.26 & 0.79 & $\begin{array}{c}14.72 \sim \\
17.80\end{array}$ & 8 & 13 & 23 & 32 & 42 & $\begin{array}{l}12.0 \sim \\
15.0\end{array}$ \\
\hline $\begin{array}{r}\text { Actin5C- } \\
\text { A } 342 . D M S O\end{array}$ & 161 & 8.81 & 0.31 & $\begin{array}{c}8.20 \sim \\
9.42\end{array}$ & 6 & 8 & 11 & 15 & 19 & $\begin{array}{l}8.0 \sim \\
8.0\end{array}$ \\
\hline $\begin{array}{r}\text { Actin5C- } \\
\text { Aß42.DWE }\end{array}$ & 168 & 15.50 & 0.60 & $\begin{array}{c}14.32 \sim \\
16.68\end{array}$ & 9 & 14 & 21 & 28 & 33 & $\begin{array}{l}13.0 \sim \\
15.0\end{array}$ \\
\hline $\begin{array}{l}\text { Actin5C- } \\
\text { A } \beta 42 . \text { SalA }\end{array}$ & 163 & 12.21 & 0.52 & $\begin{array}{c}11.20 \sim \\
13.22\end{array}$ & 7 & 11 & 16 & 22 & 35 & $\begin{array}{l}10.0 \sim \\
11.0\end{array}$ \\
\hline $\begin{array}{r}\text { Actin5C- } \\
\text { Aß42.SalB }\end{array}$ & 199 & 13.33 & 0.55 & $\begin{array}{c}12.26 \sim \\
14.40\end{array}$ & 7 & 11 & 19 & 25 & 38 & $\begin{array}{l}10.0 \sim \\
12.0\end{array}$ \\
\hline
\end{tabular}


bioRxiv preprint doi: https://doi org/10.1101/2020.05.12.089797; this version posted May 14, 2020. The copyright holder for this preprint

Table 3: Mean and median of female experimented Drosophila melanogaster lines fed with or without DWE, SalA or SalB

\begin{tabular}{|c|c|c|c|c|c|c|c|c|c|c|}
\hline \multirow[b]{2}{*}{ Name } & \multirow[b]{2}{*}{$\begin{array}{l}\text { No. of } \\
\text { subjects }\end{array}$} & \multicolumn{3}{|c|}{ Restricted mean } & \multicolumn{6}{|c|}{ Age in days at \% mortality } \\
\hline & & Days & $\begin{array}{l}\text { Std. } \\
\text { error }\end{array}$ & $\begin{array}{l}95 \% \\
\text { C.I. }\end{array}$ & $25 \%$ & $50 \%$ & $75 \%$ & $90 \%$ & $100 \%$ & $\begin{array}{l}95 \% \\
\text { Median } \\
\text { C.I. }\end{array}$ \\
\hline $\begin{array}{r}\text { Actin5C- } \\
\text { OreR.DMSO }\end{array}$ & 194 & 21.01 & 0.68 & $\begin{array}{l}19.66 \sim \\
22.35\end{array}$ & 13 & 21 & 29 & 34 & 41 & $\begin{array}{l}18.0 \sim \\
22.0\end{array}$ \\
\hline $\begin{array}{l}\text { Actin5C- } \\
\text { OreR.DWE }\end{array}$ & 198 & 21.11 & 0.75 & $\begin{array}{l}19.65 \sim \\
22.57\end{array}$ & 12 & 20 & 30 & 36 & 41 & $\begin{array}{l}17.0 \sim \\
22.0\end{array}$ \\
\hline $\begin{array}{l}\text { Actin5C- } \\
\text { OreR.SalA }\end{array}$ & 154 & 19.25 & 0.89 & $\begin{array}{l}17.50 \sim \\
20.99\end{array}$ & 9 & 17 & 28 & 36 & 44 & $\begin{array}{l}15.0 \sim \\
19.0\end{array}$ \\
\hline $\begin{array}{l}\text { Actin5C- } \\
\text { OreR.SalB }\end{array}$ & 159 & 19.65 & 0.91 & $\begin{array}{l}17.87 \sim \\
21.44\end{array}$ & 11 & 17 & 29 & 38 & 45 & $\begin{array}{l}15.0 \sim \\
18.0\end{array}$ \\
\hline $\begin{array}{c}\text { Actin5C- } \\
\text { Aß42.DMSO }\end{array}$ & 153 & 11.48 & 0.39 & $\begin{array}{l}10.71 \sim \\
12.24\end{array}$ & 8 & 11 & 15 & 19 & 23 & $\begin{array}{l}10.0 \sim \\
11.0\end{array}$ \\
\hline $\begin{array}{r}\text { Actin5C- } \\
\text { Aß42.DWE }\end{array}$ & 171 & 18.78 & 0.62 & $\begin{array}{l}17.56 \sim \\
20.00\end{array}$ & 12 & 18 & 25 & 30 & 36 & $\begin{array}{l}16.0 \sim \\
19.0\end{array}$ \\
\hline $\begin{array}{l}\text { Actin5C- } \\
\text { Aß42.SalA }\end{array}$ & 159 & 16.10 & 0.65 & $\begin{array}{l}14.83 \sim \\
17.37\end{array}$ & 10 & 15 & 22 & 28 & 34 & $\begin{array}{l}14.0 \sim \\
16.0\end{array}$ \\
\hline $\begin{array}{r}\text { Actin5C- } \\
\text { A } \beta 42 . \text { SalB }\end{array}$ & 154 & 19.87 & 0.74 & $\begin{array}{l}18.42 \sim \\
21.32\end{array}$ & 13 & 19 & 26 & 32 & 44 & $\begin{array}{l}18.0 \sim \\
20.0\end{array}$ \\
\hline
\end{tabular}

